\title{
Determination of Alpha-, Beta- and Gamma- Cellulose in Bagasse and Wheat Straw: Lignin Recovery, Characterization and Depolymerization
}

Sandip Kumar Singh ( $\sim$ loginsandeep86@gmail.com )

Georg-August-Universität Göttingen: Georg-August-Universitat Gottingen https://orcid.org/0000-00030094-6253

\section{Babasaheb M Matsagar}

National Chemical Laboratory CSIR

Paresh L Dhepe

National Chemical Laboratory CSIR

\section{Research Article}

Keywords: Holocellulose, lignin depolymerization, wheat straw, bagasse, tricin, dibenzodioxocin, spirodienone

Posted Date: February 15th, 2021

DOI: https://doi.org/10.21203/rs.3.rs-193157/v1

License: (c) (1) This work is licensed under a Creative Commons Attribution 4.0 International License. Read Full License 


\title{
Determination of Alpha-, Beta- and Gamma- Cellulose in Bagasse and Wheat Straw: Lignin Recovery, Characterization and Depolymerization
}

Sandip K. Singh ${ }^{\mathrm{a}, \mathrm{b}, \#, *}$ Babasaheb M. Matsagar ${ }^{\mathrm{a}, \mathrm{b}}$, and Paresh L. Dhepe $\mathrm{e}^{\mathrm{a}, \mathrm{b}, *}$

${ }^{a}$ Catalysis \& Inorganic Chemistry Division, CSIR- National Chemical Laboratory, Dr. Homi Bhabha Road, Pune-411 008, India.

${ }^{\mathrm{b}}$ Academy of Scientific and Innovative Research (AcSIR), New Delhi 110025, India.

\#Current Affiliation: Department of Wood Technology and Wood-based Composites, GeorgAugust-University of Göttingen, Büsgenweg 4, D-37077 Göttingen, Germany

E-mail, loginsandeep86@gmail.com; and, pl.dhepe@ncl.res.in

Tel: +91-20 2590 2024; Fax, +91-20 25902633

\begin{abstract}
Lignocellulosic biomass is an abundantly available byproduct obtained after the separation of edible parts from various crops that is a potential source to produce renewable and sustainable biofuels, chemicals, materials, and polymers, without altering the greenhouse gas emissions relative to fossil feedstocks. Valorisation of lignocellulosic biomass focuses on polysaccharides conversion to value-added chemicals and polymers. However, lignin rich of high carbon burned to generate energy and chemicals. For the development of an effective lignocellulosic biomass conversion technology to biofuels and chemicals, biomass composition analysis and their properties need to be characterized prior to biomass reactions, including polysaccharide hydrolysis and lignin depolymerization. In this work, we have determined alpha-, beta- and gamma- cellulose, pentosan, lignin, and silica percentages of wheat straw (WS) and two bagasse (BG I and II) samples. The impact of different types of biomass samples on composition, and lignin recovery by applying two-stage concentrated and dilute sulphuric acid treatment, has been discussed. Subsequent studies extended to the correlation of lignin properties and their susceptibility to depolymerization using homogeneous (1-methyl-3-(3sulphopropyl)-imidazolium hydrogen sulphate) and heterogeneous (immobilized Brønsted acidic ionic liquid) catalysts to lower molar mass aromatic fractions. Thermal, physical, and chemical properties of WS, BG, and recovered lignin samples were characterized by using UVvisible, ATR, ${ }^{13} \mathrm{C}$ CP-MAS NMR, CHNS, XRD, and TGA techniques showed substantial differences in lignin structure and properties.
\end{abstract}




\section{Highlights}

1. Determination of $\alpha-/ \beta-\& / \gamma$-cellulose, lignin, nutrients in crop residues, was done

2. Variable composition was analysed in same (BG I-II) or different (BG \& WS) residues

3. Dibenzodioxocin, spirodienone, $\&$ tricin ${ }^{13} \mathrm{C}$ NMR variable intensities characterized

4. WS recovered lignin has high amounts of ether and/ or ester linkages

5. WS lignin using a homogenous catalyst, yielded maximum product yields

\section{Keywords}

Holocellulose; lignin depolymerization; wheat straw; bagasse; tricin; dibenzodioxocin; spirodienone

\section{Abbreviations and symbols}

ILs Ionic liquids

I-BAIL Immobilized Brønsted acidic ionic liquids

BG Bagasse

WS Wheat straw

TGA Thermal gravimetric analysis

ICP-OES Inductively coupled plasma - optical emission spectrometry

SEM-EDX Scanning electron microscopy- energy dispersive X-ray spectroscopy

ATR Attenuated total reflection

UV-Vis Ultra-violet-visible spectroscopy

XRD X-ray diffraction

HHV Higher heat value

$\alpha \quad$ Alpha

$\beta \quad$ Beta

$\gamma \quad$ Gamma

MMF Monomer molecular formula

${ }^{13} \mathrm{C}$ CP-MAS NMR Cross polarized magic angle spinning nuclear magnetic resonance

$\left[\mathrm{C}_{3} \mathrm{SO}_{3} \mathrm{HMIM}_{[}\left[\mathrm{HSO}_{4}\right]\right.$ 1-Methyl-3-(3-sulphopropyl)- imidazolium hydrogensulphate

THF Tetrahydrofuran

DEE Diethyl ether

EtOAc Ethyl acetate 


\section{Introduction}

Environmental concerns and depletion of ozone layers are motivated to develop an effective conversion technology that can produce renewable chemicals, fuels, and polymers from sustainable resources, including lignocellulosic biomass. Technologies currently used to produce biofuels are primarily based on edible biomass, including corn grains, sugar syrup, and starch. (Pimentel and Burgess, 2014; Tenenbaum, 2008). Edible biomass sources are contested with food supply, and their production are also limited to provide enough amounts of fuels, chemicals, and materials (Tenenbaum, 2008). Lignocellulose biomass, including rice husks, bagasse, corn stover, and wheat straw can be considered as a substantial source for the production of renewable chemicals, and fuels that can substantially help to reduce and/ or substitute the dependency on non-renewable fossil feedstocks (Lynd et al., 1991; Somerville, 2006).

Lignocellulosic biomass is primarily composed of three major biopolymers, including cellulose, hemicellulose, and lignin (Sandip K. Singh, 2020). Cellulose and hemicellulose are communally known as holocellulose (Ragauskas et al., 2006). Holocellulose is further classified to alpha-, beta- and gamma-cellulose (for more details see the T-203 cm-99 process) (Alpha-, beta- and gamma-cellulose in pulp, T 203 cm-99, 1999; Bray and Andrews, 1923). To determine the alpha-, beta- and gamma- cellulose, several processes were employed (e.g., cooking and bleaching). However, their values in lignocellulosic biomass varied with the types of substrate, temperature, and applied method (Wells, 1921). For the determination of alpha-, beta- and gamma- cellulose in the pulp, it is crucial to have the carbon balance during the biomass utilization regardless of chemicals or biofuels production. Additionally, the determination of cellulose values in plant biomass, substantially helps to analyse the degradation of polysaccharides and lignin during pulp and paper processing. Effective utilization of polysaccharides into biofuels, chemicals and functional carbon materials is known at both laboratory and industrial scales (Corma et al., 2007). However, utilization of lignin to valuable products is still a challenge due to its recalcitrant features and association with several linkages, including ether/ester $\left(\beta-\mathrm{O}-4,5-\mathrm{O}-4^{\prime}\right)$ and condensed $\mathrm{C}-\mathrm{C}\left(\beta-5^{\prime}, \beta-\beta, 5-\right.$ 5') (Rinaldi et al., 2016; del Río et al., 2015; Mosier et al., 2005). Lignin is mainly generated as a byproduct from biorefinery, pulp and paper industries. It is commonly used as a low-grade material, including binder, additive, and burn to regenerate heat and chemicals used (Binder and Raines, 2010). 
Global sugar production is roughly 166.18 million metric tons (MMT) in 2019/2020, and with an expected consumption of approximately 177.8 MMT for 2020/2021. India is the secondlargest sugar producer globally after Brazil in 2019/2020. India produces sugar roughly 28.9 MMT that is $16.3 \%$ worldwide (M. Shahbandeh, 2020). The European Union produced the highest amounts of wheat ( $c a$. 153.5 MMT) in 2019, and India produced approximately 102.19 MMT wheat, that quantity is the third largest wheat producer worldwide (Shahbandeh, 2020). Both bagasse and wheat straw are the crop residues left after utilizing edible parts, i.e., sugar syrup and wheat grains from sugarcane and wheat, respectively. These residues are generally burned to generate heat and/ or used as cattle feed in India. However, the burning of renewable non-edible feedstocks is a concern to produce tons of toxic gases. To reduce and/ or eliminate the generation of toxic gases, and to find alternative solutions, developing an effective conversion technology of lignocellulosic biomass to chemicals, biofuels, and polymers are essential (Yanding Li et al., 2018; Alinejad et al., 2019).

Environmental and development are the main factors that affected the lignin structure over aging. Separation and isolation of lignin from biomass, are also considered that potentially altered the lignin structure during the processing (Sandip K. Singh and Dhepe, 2016b; 2018b; Chaudhary and Dhepe, 2019; Vanholme et al., 2019). In our previous works (Sandip K. Singh and Dhepe, 2016b; 2018b; Chaudhary and Dhepe, 2019) and others works (Constant et al., 2016; Sannigrahi et al., 2010), it was observed that lignin linkages, molar mass, functional groups and intensities varied either applying same procedure with different biomass or same biomass under different procedures (Sandip K. Singh, 2020).

To recover lignin from lignocellulosic biomass, several methods were reported using Kraft, soda, two-stage alkaline oxidative treatment, lignosulphate, dilute acid, enzymatic, ionic liquids, organosolv process and more (Schutyser et al., 2018; Sandip K. Singh et al., 2019; Bhalla et al., 2019; Sandip K. Singh, 2020). These processes operated at a range of reaction conditions, including temperature, time, chemical, organic solvents, ionic liquids, enzymes, pH, and alkali loadings (Mosier et al., 2005; Sandip K. Singh, 2020). The recovered lignin showed a wide range of variation regardless of physical, chemical, thermal or biological properties. These properties of lignin substantially influenced the conversion and utilization of lignin (Kozliak et al., 2016).

Bioethanol and biobutanol have been produced from concentrated sulphuric acid-treated lignocellulosic biomass, and the technologies used to generate biofuels at large scales, have 
been investigated by using concentrated sulphuric acid (Riaz et al., 2016). Lignin recovered by using concentrate sulphuric acid, associated with low contents of ether linkages, and has a high order of condensed linkages (carbon-carbon). The concentrate sulphuric acid hydrolysis lignin was depolymerized by using basic catalysts (e.g., sodium hydroxide, potassium hydroxide, and sodium carbonate) at high temperature $\left(330^{\circ} \mathrm{C}\right)$, and process produced low yields of aromatic fractions due to high percentage of condensed linkages (Riaz et al., 2016). The concentrate sulphuric acid hydrolysis lignin was converted by using supercritical ethanol in presence of formic acid at $350{ }^{\circ} \mathrm{C}$ (Riaz et al., 2016). In our previous work, we recovered concentrated sulphuric acid hydrolysis lignin from coconut coir and characterized by using several analytical techniques, and recovered lignin was depolymerized by using a solid base catalyst $(\mathrm{NaX})$ at $200{ }^{\circ} \mathrm{C}$ (Chaudhary and Dhepe, 2019). Ionic liquid (IL) is considered as Green solvents or catalysts due to their specific properties, including low vapor pressure, non-corrosive relative to mineral acids or bases, good thermal stability, and more properties (Sandip K. Singh and Savoy, 2020). Considering the specific properties of ILs, they have been applied in various reactions, including lignocellulosic biomass deconstruction, lignin depolymerization to aromatic monomers and more (Sandip K. Singh and Dhepe, 2016a; 2019; Bhalla et al., 2019).

In summary, previous studies suggested that several types of acid delignification methods can be used to recover lignin from lignocellulosic biomass. In this work, we performed two-stage concentrated and diluted sulfuric acid polysaccharides hydrolysis to recover lignin from two types of bagasse (BG I and II) and wheat straw (WS) crop residues. We extended our study to determine the composition, including alpha-, beta- and gamma- cellulose, pentosan, inorganic nutrients, and lignin of BG (I and II) and WS samples. A wide range of bulk and molecular levels analytical techniques including thermal gravimetric analysis (TGA), inductively coupled plasma - optical emission spectrometry (ICP-OES), scanning electron microscopy attached with energy dispersive X-ray spectroscopy (SEM-EDX), attenuated total reflection (ATR), ultra violet-visible spectroscopy (UV-Vis), X-ray diffraction (XRD), and ${ }^{13} \mathrm{C}$ cross polarized magic angle spinning $\left({ }^{13} \mathrm{C}\right.$ CP-MAS) NMR were applied to correlate the impact of crop residues over the lignin recovery and properties. In our previous works, we have screen a set of different ILs, and the optimized catalysts used for this work (Sandip K. Singh and Dhepe, 2016a; 2019). Catalytic efficacy of homogeneous (i.e., 1-methyl- 3-(3-sulphopropyl) imidazolium hydrogen sulphate $\left[\mathrm{C}_{3} \mathrm{SO}_{3} \mathrm{HMIM}\right]\left[\mathrm{HSO}_{4}\right]$ ) and heterogeneous (i.e., immobilized Brønsted acidic ionic liquid, I-BAIL) acidic ionic liquids, was correlated with lignin properties to susceptible for depolymerization to low molar mass aromatic fractions. 


\section{Experimental}

\subsection{Materials and methods}

\subsubsection{Materials}

Bagasse (BG) I and II were collected from Maharashtra and Uttar Pradesh states of India. Wheat straw (WS) was collected from Uttar Pradesh, India. Prior to use, BG I and II and WS samples were meshed to get uniform particle size $(c a .45 \mu)$ by passing through a Jayant test sieves (Mesh \# B.S.S-30, ASTM-35 Made in India). Ferroin solution (AR 0.025 M Loba chemie, India), ferrous ammonium sulphate hydrate (FAS, 98.50\%, Loba chemie, India), sulphuric acid (98\%, Loba chemie, India), sodium chlorite $\left(\mathrm{NaClO}_{2},(80.0 \%\right.$, Thomas baker, India), glacial acetic acid (99.8\% Thomas Baker, India), hydrofluoric acid (40.0\%, Loba chemie, India), methanol (99.80\%, Loba chemie, India), isopropyl alcohol (>99.50\%, Loba chemie, India), hydrofluoric acid (40.0\%, Loba chemie, India), hydrochloric acid (35.50\%, Loba chemie, India), nitric acid (69.0-72.0\%, Loba chemie, India), sodium hydroxide (98.0\%, Loba chemie, India), and potassium dichromate (99.50\%, Loba chemie, India), were purchased and used without any further purification unless mentioned.

\subsection{Lignin recovery}

Recovery of concentrated sulfuric acid insoluble lignin from bagasse (BG I and II) and wheat straw (WS), was done using a well-known method with a few minor modifications (Sannigrahi et al., 2008; Samuel et al., 2010). Oven dried sample ( 1.0 g) was taken in a beaker $(100 \mathrm{~mL}$ capacity) and added $\mathrm{H}_{2} \mathrm{SO}_{4}(15 \mathrm{~mL}, 72 \% \mathrm{wt} / \mathrm{wt})$ solution. The sample was retained in a water bath at $30 \pm 1{ }^{\circ} \mathrm{C}$ for $1 \mathrm{~h}$. The reaction mixture was stirred with a glass rod with a pause of 10 min. Thereafter completion of reaction, mixture was diluted with hot distilled water $\left(80{ }^{\circ} \mathrm{C}\right)$ and poured this sample in a $1000 \mathrm{~mL}$ round bottom flask $(\mathrm{RB})$. The volume of reaction mixture was maintained up-to $600 \mathrm{~mL}$ by adding additional hot water. The reaction mixture was refluxed in an oil bath for $4 \mathrm{~h}$, it was then transferred in a water bath at $50{ }^{\circ} \mathrm{C}$, for $16 \mathrm{~h}$. The precipitate was filtered by using a G2 crucible and washed with hot water to remove the contamination of sulphuric acid and impurities. The filtrate was processed for UV-Vis spectroscopy to quantify the acid soluble lignin (for more details, see Section S1.5, ESM). The recovered concentrated sulfuric acid hydrolysis lignin as a precipitate was air dried for $6 \mathrm{~h}$ and transferred then in an oven at $60 \pm 2{ }^{\circ} \mathrm{C}, 6 \mathrm{~h}$. Finally, precipitate was transferred in a vacuum oven at $100 \pm 2{ }^{\circ} \mathrm{C}$, below $1.01 \mathrm{bar}$, for $4 \mathrm{~h}$ to remove moisture. The recovered precipitate is 
named a concentrated sulphuric acid hydrolysis lignin. The recovered lignin sample was thoroughly characterized by using a series of analytical techniques.

Concentrated sulphuric acid hydrolysis lignin and acid soluble lignin were yielded with $20 \pm 2 \%$ wt/wt dried biomass with 95 $\pm 3 \%$ mass balance (Figure 1, Section S1.4, Table S1, ESM). All the reactions were replicated to reproduce the results, and approximately 5\% error noted.

\subsection{Quantification of alpha-, beta- and gamma- cellulose}

Polysaccharides mainly composed of alpha-cellulose, beta-cellulose, and gamma-cellulose, and hemi/cellulose are known as holocellulose in layered plant cell walls. The compositional analysis including cellulose (alpha-, beta- and gamma- cellulose), pentosan, lignin, ash, and silica, of BGs and WS samples, was done by using a known method (T-203 cm-99 process) (Alpha-, beta- and gamma-cellulose in pulp, T 203 cm-99, 1999; Bray and Andrews, 1923), (Figure 1) (For more details, see the Section S1, ESM). The obtained composition of three samples are in line with reported values with a minor difference (Templeton et al., 2010; Rezende et al., 2011; Kumar et al., 2010; MontaÃ \pm ez Valdez et al., 2008).

\subsection{Characterization}

We collected BG and WS crop residues, and thoroughly characterized in our previous studies (Sandip K. Singh and Dhepe, 2018b; 2016b). In this work, we have used several bulk and molecular levels techniques, including elemental analysis, TGA, ICP-OES, SEM-EDX, ATR, UV-Vis, XRD, and ${ }^{13} \mathrm{C}$ CP-MAS NMR, to understand the physical, chemical and thermal properties of crop residues and recovered lignin samples (for more details, sample preparation and instruments, see Section S2, ESM). The properties of recovered lignin, were correlated and investigated for conversion to low molar mass fractions by using homogeneous $\left[\mathrm{C}_{3} \mathrm{SO}_{3} \mathrm{HMIM}\right]\left[\mathrm{HSO}_{4}\right]$ ) and heterogeneous I-BAIL ILs as a catalyst (for more details on synthesis and characterization, see our previous reports) (Sandip K. Singh and Dhepe, 2016a; 2018c; Sandip K. Singh and Savoy, 2020). We have screened a range of reaction conditions including temperature, pressure, time, solvents, lignins, catalysts, etc., and optimized reaction conditions were selected for lignin conversion in this work (Sandip K. Singh and Dhepe, 2016a; Sandip Kumar Singh et al., 2018; Sandip K. Singh and Dhepe, 2018a; c; 2019). 


\section{Results and discussion}

\subsection{Composition analysis}

Plant biomass is mainly composed of cellulose, hemicellulose, and lignin in maximum amounts, whereas, silica, extractive, and inorganic nutrients are present in minimum amounts. The utilization of cellulose and hemicellulose for biofuels, chemicals, polymers and more, is a well procured process at the industrial level (Sandford and Baird, 1983). The major advantages of using bagasse (BG) and wheat straw (WS), are their profuse availability in India. These crop residues are eventually burned to generate heat, and this process generates tons of toxic gases. In this work, two BGs and WS samples were screened for acidic lignin recovery, characterization and further depolymerization to low molar mass of phenolic products. Figure 1 shows the composition of these biomass samples. BG samples show the higher amounts of quantified cell wall structural biopolymers (i.e., holocellulose (alpha-, beta- and gammacellulose) and lignin $(89 \pm 1 \%)$ ), and contain low amounts of silica. Based on the approximate composition of two BG samples, it is assumed that the structural properties of BGs (e.g., cell wall association, mass density, lignin structures, etc.) do not statistically differ. It could be then hypothesized that these BG samples can exhibit similar behaviour in terms of characterization and susceptibility for conversion.

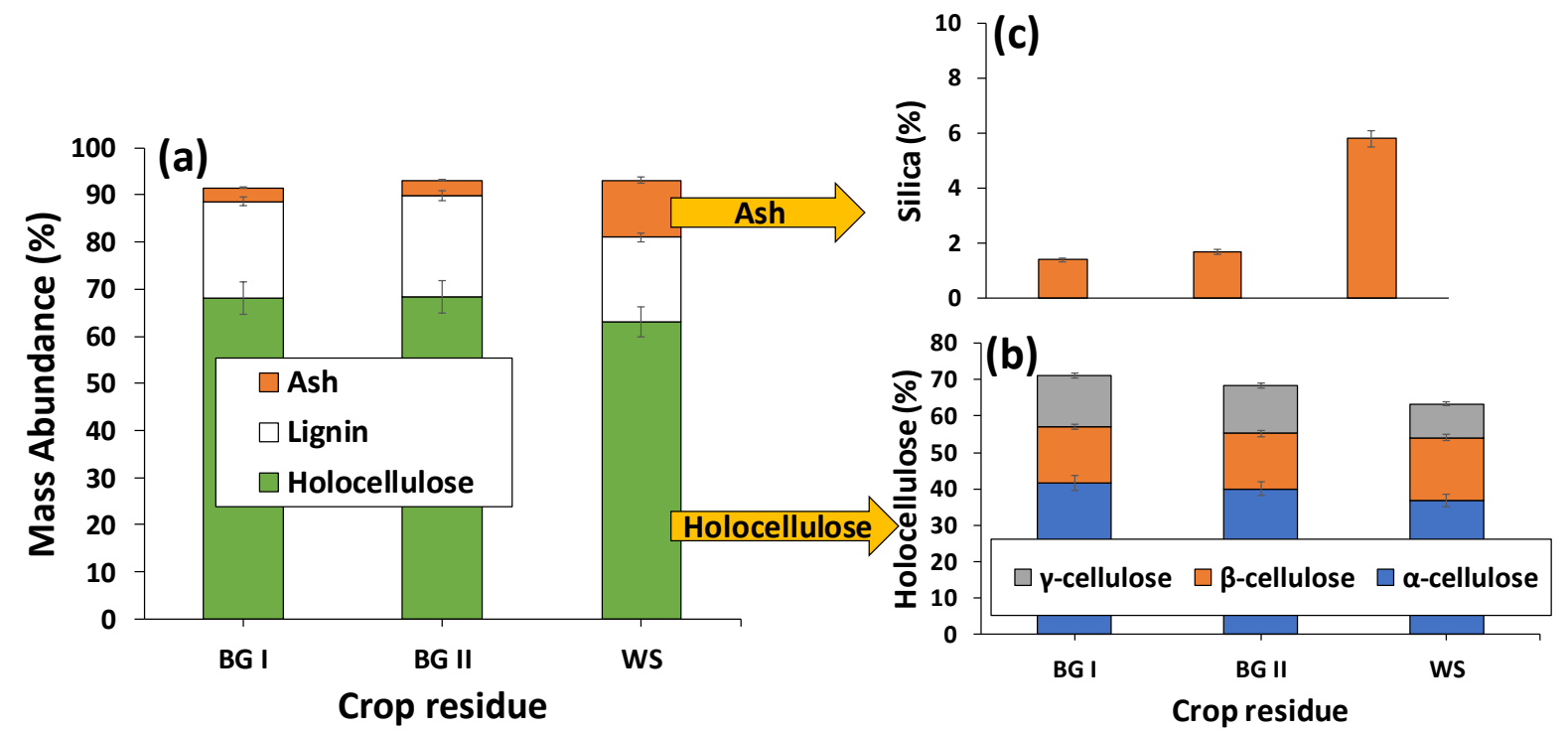

Fig. 1. Composition analysis of BG I and II and WS. (a) mass abundance (b) holocellulose (i.e., alpha-, beta- and gamma-cellulose) fraction, and (c) silica content in ash fraction.

\subsection{Physico-chemical properties}

\subsubsection{Lignin and crop residues}

To determine how the type of biomass, including similar and different species impact over the recovered lignin properties, and ultimately, their suitability for conversion to low molar mass 
fractions. Recovered lignin and crop residues samples were subjected to characterization using a range of experimental techniques (for more details, see Section S2, ESM).

Figure 2 shows the XRD diffractogram of recovered lignin samples. Peaks presented at 15.55 , 17.37, 22.08 and $34.98^{\circ}$ in crop residues, are disappeared in recovered lignin (For more details on XRD spectra of crop residues, please see our previous work (Sandip K. Singh and Dhepe, 2018b). As expected, thereafter two-stage acidic hydrolysis, complete removal of polysaccharides observed. In isolated lignin, no impurity peaks, that represent for cellulose $\sim 19.8, \sim 22.5^{\circ}$ (Tang et al., 2012) for crystalline, and $\sim 16, \sim 18^{\circ}$, (Wu et al., 2010; Oh et al., 2005) for amorphous, were characterized. A wide range of (12.5-32.5 ) XRD patterns characterized in recovered lignin, that confirmed the recovered lignin samples are amorphous (Sarkanen, 1963). A sharp peak in WS derived lignin relative to BGs, observed at $26.59^{\circ}$ corresponds to Si (JCPDS file No. 33-1161). WS residue contained maximum amounts of ash contents (Fig. 1), that included maximum silica (Fig. 1c). The presence of maximum amounts of silica, that is in good agreement with an XRD intense peak at $26.59^{\circ}$. As observed from Figure $2 \mathrm{~B}$, a wide range of $2 \Theta$ from 20.64 to $36.05^{\circ}$, that indicates lignin amorphous characteristic (Gomide et al., 2020).

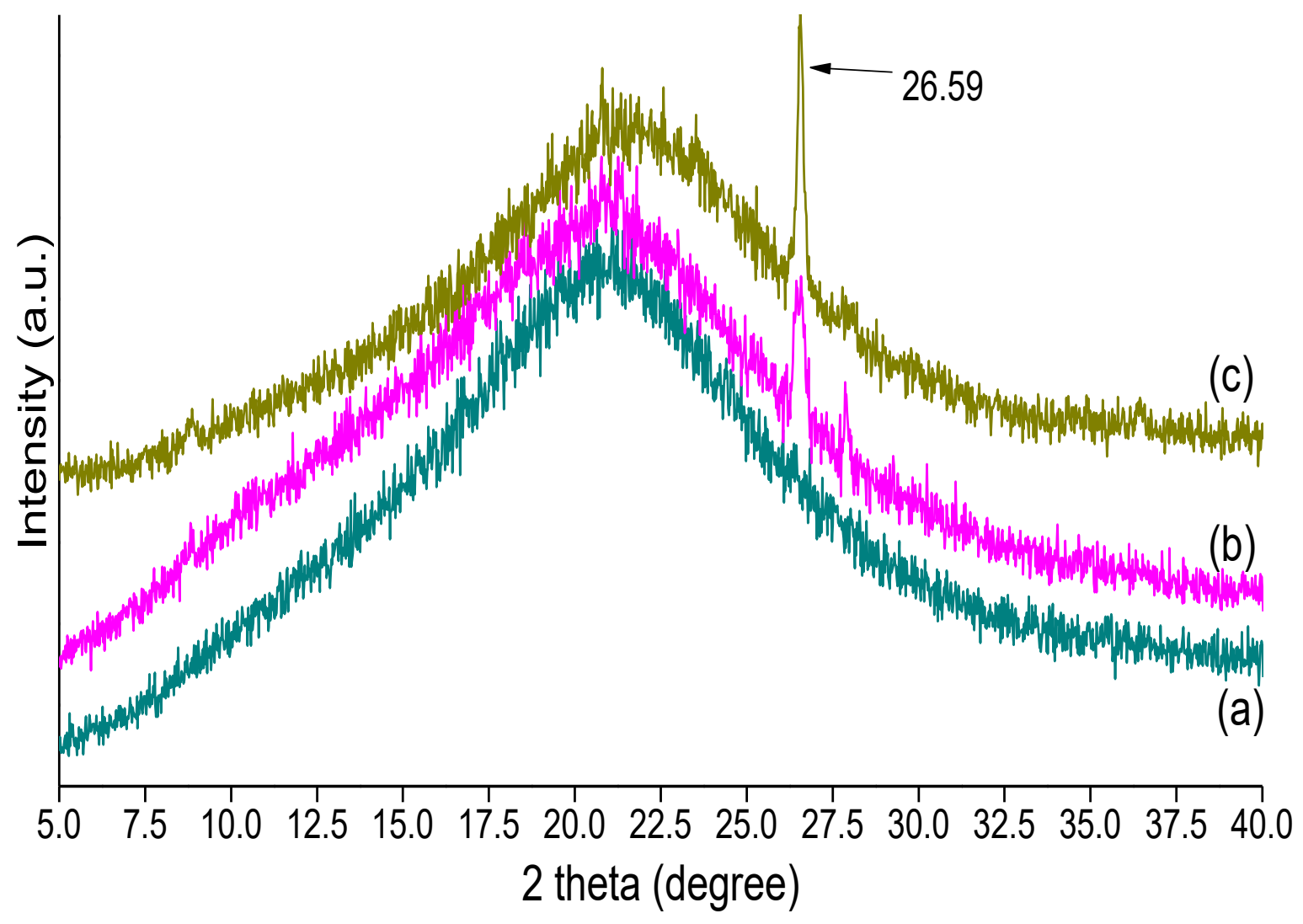

Fig. 2. XRD spectra of (a) BG I, (b) BG II, (c) WS, recovered lignin. 
SEM analysis is a unique and versatile technique to define the structure of crop residues and lignin (Ghaffar and Fan, 2013). SEM images of BGs and WS samples were taken and showed uni-structural morphologies (images not shown). Spherical morphologies were seen for lignin derived from bagasse, whereas lignin derived from WS, showed a non-structural image. The structural difference of recovered lignin from different crop samples, can plausible explain due to the presence of high amounts of inorganic contents (Fig. 1). EDX analysis was performed to analyse the carbon, oxygen, sulphur, silicon, etc., of recovered lignin samples. Presence of sulphur content in lignin samples, could be explained based on the method used to recover lignin.

Degradation or weight loss as a function of temperature analysed using a TGA. The occurrence of sample weight loss can be caused by oxidation and decomposition reactions as well physicochemical properties including vaporization, sublimation, and desorption (H. M. Ng et al., 2018). TGA analysis of lignin derived from BG (I and II) and WS samples, was performed in air (TGA graph not shown). The graph represents the three-stages of weight loss. Initial weight loss of sample was observed in a range of $50{ }^{\circ} \mathrm{C}$ to $175^{\circ} \mathrm{C}$. This weight loss can be plausibly explained due to release of surface adsorb water. Lignin is featured with primarily three moieties, including sinapyl $(\mathrm{S})$, coniferyl $(\mathrm{G})$ and $p$-coumaryl $(\mathrm{H})$, alcohol units (Sandip K. Singh, 2019). These alcohols are linked with various kind of bonds including C-O-C (foremost ester/ether) and C-C (minor). The second weight loss $\left(\sim 200\right.$ to $\left.\sim 350{ }^{\circ} \mathrm{C}\right)$ in lignin samples occurred due to the decomposition of various linkages and attached aliphatic units (Sandip K. Singh and Dhepe, 2016b; 2018b). Finally, the weight loss from $\sim 350{ }^{\circ} \mathrm{C}$ to $\sim 600{ }^{\circ} \mathrm{C}$ observed due to the decomposition of aromatic moieties in the lignin structure. Thereafter, no further weight loss was observed. Approximately $2.5 \%$ solid remained as a constant weight until 800 ${ }^{\circ} \mathrm{C}$. The remaining weight was ash content present in the lignin sample. The weight of left residues is also in agreement with the weight of ash, observed with composition analysis of WS sample. In addition, the presence of inorganic content and metal amounts in crop residues, is confirmed and quantified by ICP-OES analysis (Table S2, ESM) respectively.

The elemental mapping, including carbon, hydrogen, and oxygen is required for characterizing the chemical contents in biomass. The energy released during the combustion or oxidation process is directly correlated to the sum of carbon and hydrogen contents as a function of energy values in biomass. In contrast, the maximum amounts of oxygen and nitrogen contents have low heat values, and that can decrease the energy efficacy of materials. Table 1 shows the elemental analysis of recovered lignin. Crop residues have maximum amounts of oxygen 
relative to recovered lignin (Sandip K. Singh and Dhepe, 2018b). Therefore, the determined higher heat value (HHV) of crop residues has approximately half to lignin HHV. Crop residues contained the lower amounts of $\mathrm{C} / \mathrm{O}$ ratio (average of three crop residues; 1.16) relative to lignin (average of three recovered lignin; 2.53). Lignin derived from BG II residue, has a high heat efficacy relative to lignin recovered from BG I and WS. Recovered lignin samples associated with low amounts of sulphur, and the sulphur presence in lignin, can be explained based on the method used to recover lignin. The presence of acidity in lignin samples, can be explained based on the acidic solution, that was used to solubilize polysaccharides during the lignin recovery. The HHV determination of crop residues and recovered lignin samples was done using the following equation 1.

$$
\mathrm{HHV}\left(\frac{\mathrm{MJ}}{\mathrm{kg}}\right)=0.3383 \times \mathrm{C}+1.442 \times\left(\mathrm{H}-\frac{\mathrm{O}}{8}\right)
$$

Whereas $\mathrm{C}=\%$ wt. basis of carbon, $\mathrm{H}=\%$ wt. basis of hydrogen and $\mathrm{O}=\%$ wt. basis of oxygen.

Table 1. Elemental mapping of BGs I- II and WS recovered lignin (oven dry basis)

\begin{tabular}{|c|c|c|c|c|c|c|c|c|}
\hline & $\mathbf{C}$ & $\mathbf{H}$ & $\mathbf{O}^{[\mathbf{a}]}$ & $\mathbf{S}$ & $\mathbf{M M F}^{[\mathbf{b}]}$ & $\begin{array}{c}\mathbf{( w t \% )} \\
\mathbf{a s h}\end{array}$ & $\mathbf{H H V ^ { [ \mathbf { c } ] }}$ & $\mathbf{p H}$ \\
\hline BG I & 58.2 & 5.5 & 35.3 & 1.0 & $\mathrm{C}_{8.4} \mathrm{H}_{9.4} \mathrm{O}_{3.9} \mathrm{~S}_{0.1}$ & 10 & 15.8 & 2.8 \\
\hline BG II & 64.4 & 6.9 & 29.7 & 1.2 & $\mathrm{C}_{9.3} \mathrm{H}_{11.9} \mathrm{O}_{3} \mathrm{~S}_{0.1}$ & 6 & 19.8 & 2.7 \\
\hline WS & 58.7 & 6.2 & 34.1 & 1.0 & $\mathrm{C}_{8.5} \mathrm{H}_{10.7} \mathrm{O}_{3.7} \mathrm{~S}_{0.1}$ & 25 & 17.6 & 2.7 \\
\hline
\end{tabular}

Where [a]calculation based on elemental analysis by using by using (wt of $\mathrm{O} \%$, ash free) $=100-(\mathrm{wt}$ of $\mathrm{C}+\mathrm{H}+\mathrm{S})$. [b] MMF- monomer molecular formula and [c] HHV- higher heat value $\left(\mathrm{MJkg}^{-1}\right)$.

The presence of chromophoric groups in lignin, is characterized using UV-Vis absorption spectroscopy. Lignin has a high UV absorption due to the presence of various functional groups and aromatic moieties. These groups and moieties have a high rate of $\Pi$ vacant orbitals. The recovered lignin samples were processed for UV-Vis absorption study, and the obtained results are shown in Fig. 3. Lignin is associated with high amounts of aromatic units, and these units have several $\Pi$ vacant orbitals. Therefore, the more intense peak is observed around $205 \mathrm{~nm}$ that associates to $\Pi-\Pi^{*}$ transition of aromatic, alkene, or alkyne unit (Antosiewicz and Shugar, 2016). The appearance of mono/di-substituted aromatic phenolic rings (e.g., hydroxyl, methoxy, aryl oxide groups, etc.) in lignin, is observed around $230 \mathrm{~nm}$. Free and/ or etherified 
hydroxyl groups attached to the phenolic structure are observed around $280 \mathrm{~nm}$ (Musha and Goring, 1975). The absorption band $\sim 318 \mathrm{~nm}$ indicates the presence of aromatic conjugated structure $(C-\alpha, C=C$ and $C=O)$ in recovered lignin samples (Shulga et al., 2012).

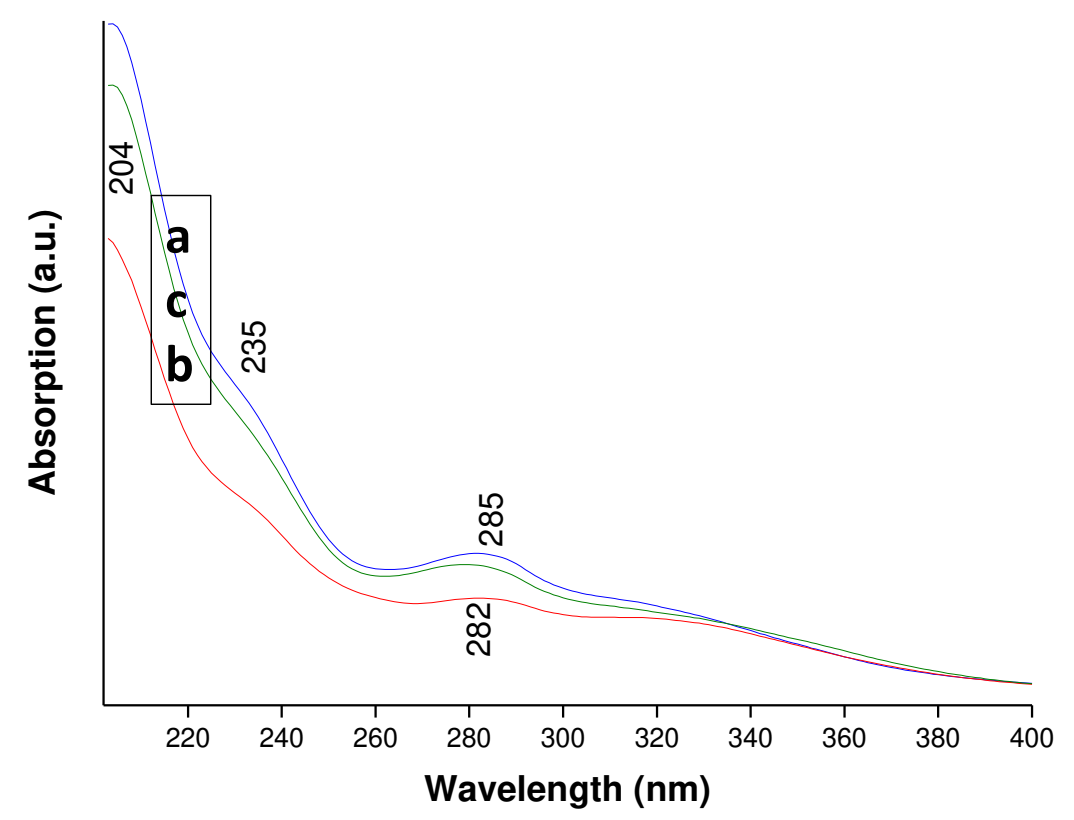

Fig. 3. UV-Visible spectra of a- BG I, b- BG II and c- WS, recovered lignin.

Note: $\sim 0.01 \% \mathrm{wt} / \mathrm{v}$ lignin solution prepared in methanol.

The presence of different types of functional groups in recovered lignin was analysed using an ATR (Alfa Bruker) technique. Fig. 4 shows the ATR spectra of recovered lignin from BGs and WS crop residues with a typical band assignment from 750-1850 and $2750-3800 \mathrm{~cm}^{-1}$. A comparison study of lignin was done based on the literature (Long et al., 2012; Weiying Li et al., 2011; Strassberger et al., 2015; Hergert, 1971). A band at $3364 \mathrm{~cm}^{-1}$ was assigned to the hydroxyl groups attached to phenolic, or side chain aliphatic unit. The peaks at 2923 (intense peak in BG I) and $2852 \mathrm{~cm}^{-1}$ were characterized for $\mathrm{C}-\mathrm{H}$ stretching vibrations in the methoxy, methyl, or methylene group. The band $\sim 1733 \mathrm{~cm}^{-1}$ assigned to the presence of unconjugated, conjugated carbonyl or aromatic carboxyl groups with almost similar intensities in all lignin samples. The bands at 1642,1602,1508, 1454 and $\sim 1420 \mathrm{~cm}^{-1}$, were assigned for stretching of benzene ring in syringyl, guaiacyl and $p$-coumaryl alcohol moieties. The presence of $1212 \mathrm{~cm}^{-}$ 1 and $1043 \mathrm{~cm}^{-1}$ peaks was noted for guaiacyl units, (Hergert, 1971) and these peaks are more intense in lignin derived from BG I. The peak at $1172 \mathrm{~cm}^{-1}$ assigned for $p$-coumaryl alcohol. The appearance of these peaks indicates the recovered lignin samples were generally associated with $\mathrm{G}$ and $\mathrm{H}$ moieties. In addition, absorbance peaks of $\mathrm{G}$ unit (1212 and $\left.1043 \mathrm{~cm}^{-1}\right)$ in lignin 
samples, were characterized more intense to $\mathrm{H}\left(1167 \mathrm{~cm}^{-1}\right)$. These results showed that the guaiacyl moiety is present in high concentrations in recovered lignin (Hussin et al., 2013). The appearance of more intense peaks $\sim 280 \mathrm{~nm}$ in UV-Vis, also affirmed that guaiacyl moiety is present with high concentration relative to $\mathrm{S}$ and $\mathrm{H}$ moieties (Fig. 3). A shoulder peak was noted with almost similar intensities at $\sim 1359 \mathrm{~cm}^{-1}$ in lignin recovered from BG II and WS samples. A strong band at $1087 \mathrm{~cm}^{-1}$ characterized for $\mathrm{C}-\mathrm{H}$ deformation of secondary alcohols, or by $\mathrm{C}=\mathrm{O}$ stretching vibrations (For more details of peak assignments and respective wavenumber see Table 2).

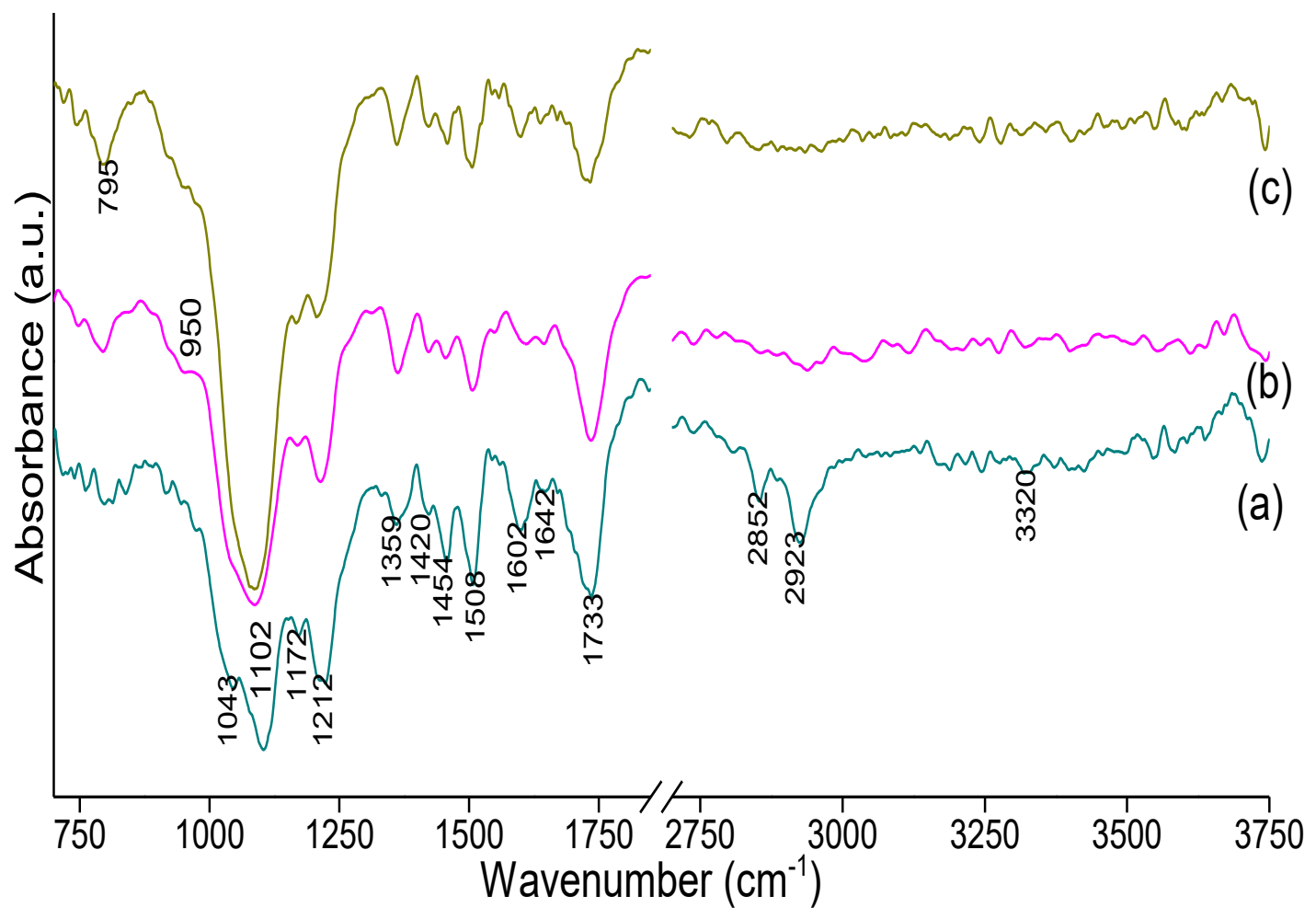

Fig. 4. ATR spectra of recovered lignin from (a) BG I, (b) BG II, and (c) WS.

Table 2. ATR band assignments of recovered lignin from BG I, BG II and WS

\begin{tabular}{|c|l|c|c|c|}
\hline \multirow{2}{*}{ Band $\left(\mathbf{c m}^{-1}\right)$} & \multicolumn{1}{|c|}{ Assignment } & \multicolumn{3}{|c|}{ Wavenumber $\left(\mathbf{c m}^{-1}\right)$} \\
\cline { 3 - 5 } & & BG I & BG II & WS \\
\hline $3400-3300$ & O-H stretching & 3365 & 3364 & 3370 \\
\hline $2960-2920$ & $\begin{array}{l}\text { C-H asymmetric stretching in methyl or methylene } \\
\text { group }\end{array}$ & 2923 & 2935 & 2935 \\
\hline $2860-2830$ & $\begin{array}{l}\text { C-H symmetric stretching in methyl or methylene } \\
\text { group }\end{array}$ & 2852 & 2852 & 2850 \\
\hline $1750-1800$ & C=O stretching anhydride, ester or aldehyde group & - & - & - \\
\hline $1740-1680$ & C=O stretching in unconjugated ketone, carbonyl & 1737, & 1730, & 1734 \\
\hline
\end{tabular}




\begin{tabular}{|c|l|c|c|c|}
\hline $1670-1620$ & $\begin{array}{l}\mathrm{C}=\mathrm{O} \text { stretching in conjugated } p \text {-substituted aryl } \\
\text { ketones }\end{array}$ & 1643 & 1643 & 1637 \\
\hline $1610-1590$ & Aromatic skeleton vibration plus C=O stretching & 1598 & 1611 & 1598 \\
\hline $1515-1505$ & Aromatic skeleton vibrations & & 1506 & 1505 \\
\hline $1470-1450$ & C-H deformation (asymmetric in $-\mathrm{CH}_{3}$ or $\left.-\mathrm{CH}_{2}-\right)$ & 1457 & 1454 & $\begin{array}{c}1457 \\
1421\end{array}$ \\
\hline $1370-1350$ & $\begin{array}{l}\text { Aliphatic C-H stretching in } \mathrm{CH}_{3}\left(\text { not }-\mathrm{OCH}_{3}\right) \text { or } \\
\text { phenolic }-\mathrm{O}-\mathrm{H}\end{array}$ & 1357 & 1362 & 1360 \\
\hline $1230-1200$ & $\begin{array}{l}\text { C-C plus, C-O plus, C=O stretching }(G \text { condensed } \\
>G \text { etherified, typical of } G \text { units) }\end{array}$ & 1221 & 1206 & 1205 \\
\hline $1180-1160$ & Typical for $H, G, S$ units of lignin & 1170 & 1167 & 1170 \\
\hline $1080-1100$ & $\begin{array}{l}\mathrm{C}-\mathrm{O} \text { deformations of secondary alcohols or } \\
\text { aliphatic ether aromatic } \mathrm{C}-\mathrm{H}\end{array}$ & 1102 & 1087 & 1087 \\
\hline $1040-1060$ & $\mathrm{~S}=\mathrm{O}$ stretching & 1047 & 1048 & 1051 \\
\hline
\end{tabular}

The solution state or solid-state NMR study was used to characterize the lignin morphology (Hatfield et al., 1987). Recovered lignin samples were subjected to solid-state ${ }^{13} \mathrm{C} \mathrm{CP}-\mathrm{MAS}$ NMR using $46.7 \mu$ s acquisition time (AQ), and 21,000 scans. A Bruker Avance- $300 \mathrm{MHz}$ spectrometers operating at $75.47 \mathrm{MHz}$ frequency, was used. Approximately $200 \mathrm{mg}$ dried lignin was taken to record ${ }^{13} \mathrm{C}$ CP-MAS NMR spectra (Section S2, ESM). An adamantine molecule as an internal standard was used for ${ }^{13} \mathrm{C} \mathrm{CP}-M A S$ NMR. A comparison study of ${ }^{13} \mathrm{C}$ CP-MAS NMR for recovered lignin samples is done with available literature (Nimz et al., 1981; Holtman et al., 2006; Almendros et al., 1992).

${ }^{13} \mathrm{C}$ CP-MAS NMR of lignin mainly divided into three sections, alkyl ( $\left.\delta_{\mathrm{C}}(\mathrm{ppm}) 10-50\right)$, alkyl and/or aryl attached to heteroatom "O” ( $\delta_{\mathrm{C}}(\mathrm{ppm})$ 50-90) and finally aryl ( $\left.\delta_{\mathrm{C}}(\mathrm{ppm}) 90-150\right)$. Alkyl side chains including - $\underline{\mathbf{C}} H_{3},-\underline{\mathbf{C}} \mathrm{H}_{2-},-\underline{\mathbf{C}} \mathrm{H}_{-},-\underline{\mathbf{C}}-, \underline{\mathbf{C}} \mathrm{H}_{3} \mathrm{CO}-$, etc., are appeared in maximum numbers in recovered lignin- that is derived from BG II crop residue whereas the most intense peaks are presented in WS derived lignin (For more details of ${ }^{13} \mathrm{C} \mathrm{CP}-\mathrm{MAS}$ spectra and peak assignments, see Fig. 5 and Table 3).

Methoxy $\left(-\mathrm{OCH}_{3}\right)$ groups were noted in all lignin samples with variable peak intensities. BG I and WS recovered lignin appeared almost similar intensities whereas low intense peak for methoxy groups, observed for BG II derived lignin. ${ }^{13} \mathrm{C}$ NMR peak for $\mathrm{A}_{\alpha}, \mathrm{A}_{\beta}$ or $\mathrm{A}_{\gamma}$ in $\beta-\mathrm{O}-4$ ' substructures, presented in recovered lignin samples with variable intensities. The $\mathrm{C}_{\beta}$ carbon in the dibenzodioxocin substructure appeared in lignin recovered from WS. 
The peak for $\mathrm{C}_{8}\left(\mathrm{~T}_{8}\right)$ and $\mathrm{C}_{2,6}$ carbons in tricin $\left(\mathrm{T}^{\prime}{ }_{2}, 6\right)$ substructure, appeared in all lignin. Fig. 5 shows the more intense signal for tricin ( $\left.\mathrm{T}_{2}^{\prime}, 6\right)$ in BG II derived lignin. Peaks including $\mathrm{C}_{3,5}$ and $\mathrm{C}_{2,6}$ for $p$-hydroxyphenyl units appeared in all recovered lignin samples whereas the peak intensities for $\mathrm{C}_{2,6} p$-hydroxyphenyl units presented in high concentration in lignin recovered from BG I. The $\mathrm{C}_{\alpha}$ and $\mathrm{C}_{\beta}$ carbons in cinnamyl alcohol appeared in lignin-derived from BG II. An etherified $\mathrm{C}_{3}$ and $\mathrm{C}_{4}$ in guaiacyl $(G)$ carbons, characterized in all lignin samples, whereas lignin recovered from WS, has more intense peaks. The $\mathrm{C}_{\alpha}\left(\beta-\mathrm{O}-4^{\prime}\right.$ 'substructure $\left.\left(\mathrm{A}_{\gamma}\right)\right)$, linked units with $\alpha-\mathrm{C}=\mathrm{O}$, appeared in all lignin with almost similar intensities. The peak for $\mathrm{C}=\mathrm{O}$ in spirodienone units appeared in WS-derived lignin. The $\alpha-\mathrm{C}=\mathrm{O}$ in $\beta-\mathrm{O}-4$ ' substructures (A $\gamma)$ units appeared with low intensities in all lignin. However, besides these peaks, few more peaks are observed in recovered lignin samples (please refer to Table 3 for more detail). 

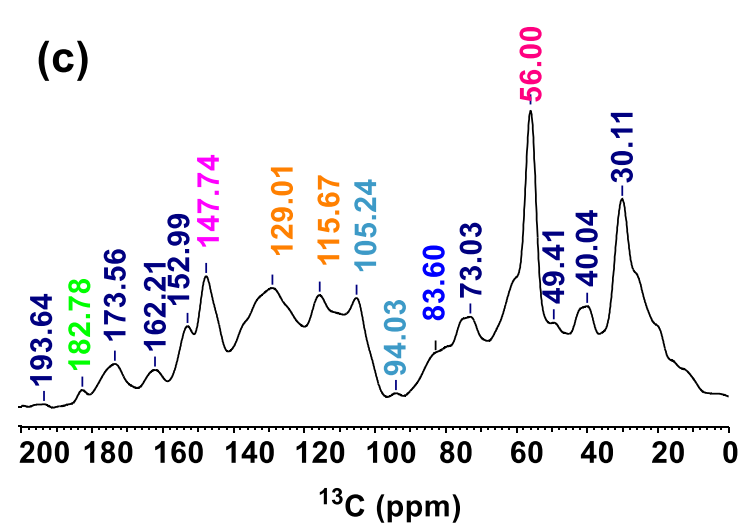

(b)

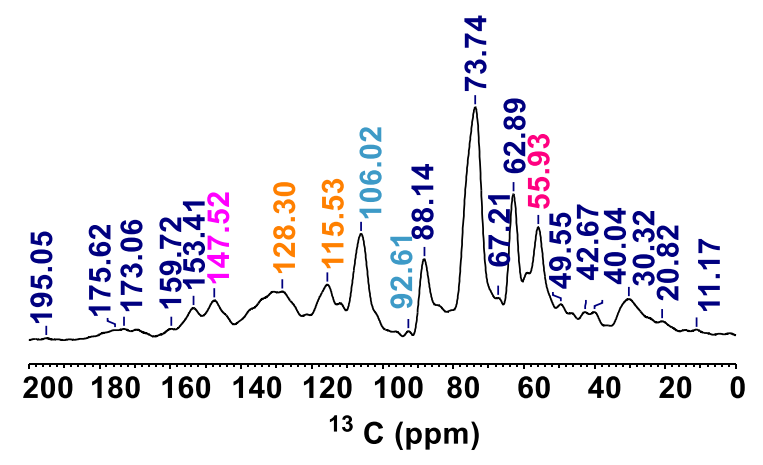

(a)

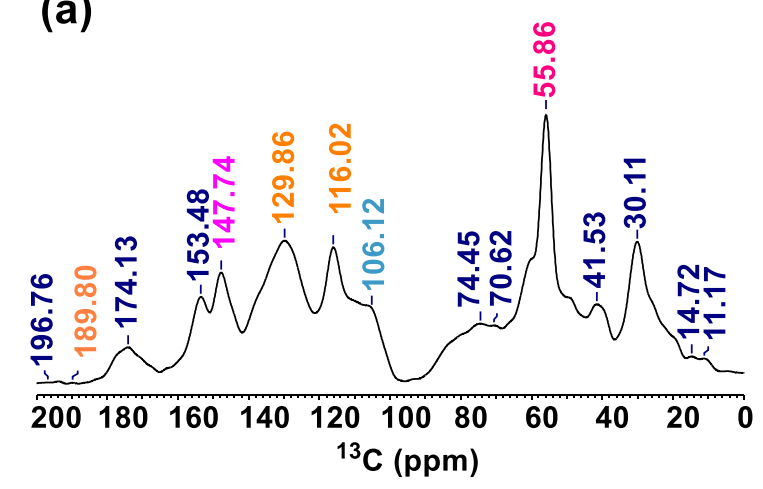

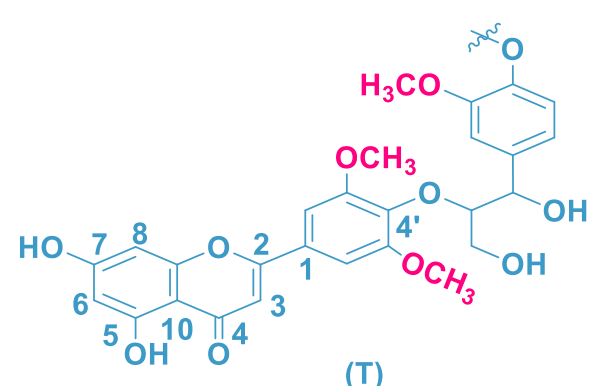

tricin

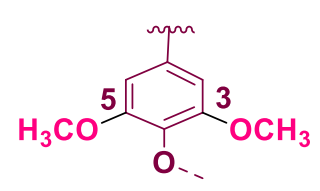

(S) syringyl

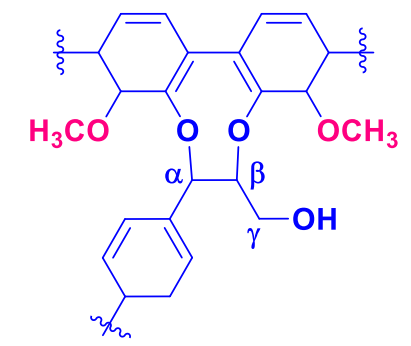

(C)

dibenzodioxocin, (5'-5", $\alpha-0-4 / \beta-0-4 / \alpha-\beta)$
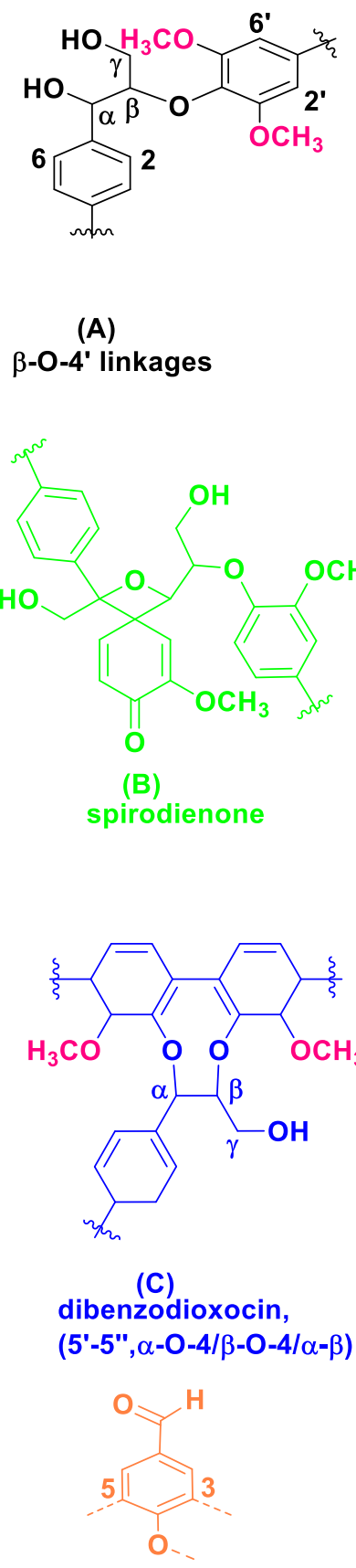

(A)

$\beta-0-4$ ' linkages

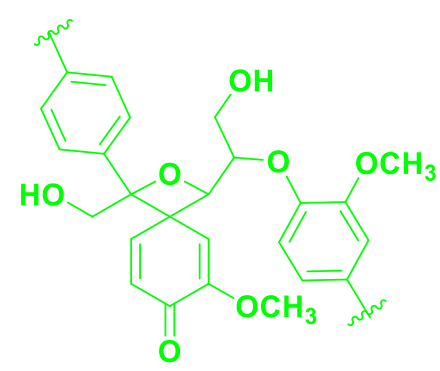

(B)

spirodienone

benzaldehyde<smiles>COc1cc(C)cc(OC)c1OC</smiles>

(G)

guaiacyl p-hydroxyphenyl

Figure 5. Solid state ${ }^{13} \mathrm{C}$ CP-MAS NMR spectra of lignin derived from (a) BG I, (b) BG II and (c) WS. 
Table 3. Assignments of ${ }^{13} \mathrm{C}$ CP-MAS NMR of lignin derived from BG I, BG II and WS .

\begin{tabular}{|c|c|c|c|}
\hline \multirow{2}{*}{ Bonding in lignin } & \multicolumn{3}{|c|}{ Peak assignment $\left(\delta_{\mathrm{C}}\right.$ ppm) } \\
\hline & BG I & BG II & WS \\
\hline Terminal $-\mathrm{CH}_{3}$ group & 14.72 & - & - \\
\hline$-\mathrm{CH}_{3}$ group in acetylated xylan & - & 20.82 & - \\
\hline$-\mathrm{CH}_{2}$ - alkyl group & 30.11 & 30.32 & 30.11 \\
\hline$\alpha$-carbon $\mathrm{CH}_{2}$ with aliphatic substituted group & - & 42.62 & - \\
\hline $\mathrm{C}-\mathrm{H}$ in methoxy group & 55.86 & 55.93 & 56.00 \\
\hline $\mathrm{C}_{\gamma}$ in $\beta$-O-4' substructures $\left(\mathrm{A}_{\gamma}\right)$ & - & 62.89 & - \\
\hline $\mathrm{C}_{\gamma}$ in $\beta$-O-4' substructure $\left(\mathrm{A}_{\gamma}\right)$ linked units with $\alpha \mathrm{C}=\mathrm{O}$ & 70.62 & - & - \\
\hline $\mathrm{C}_{\alpha}$ in $\beta$-O-4' substructure $\left(\mathrm{A}_{\alpha}\right)$ & 74.45 & 73.74 & 73.03 \\
\hline $\mathrm{C}_{\beta}$ in dibenzodioxocin substructure $\left(\mathrm{C}_{\beta}\right)$ & - & - & 83.60 \\
\hline $\mathrm{C}_{\beta}$ in $\beta$-O-4-linked unit $\left(\mathrm{A}_{\beta}\right)$ & - & 88.14 & - \\
\hline $\mathrm{C}_{8}$ in tricin $\left(\mathrm{T}_{8}\right)$ & - & 92.61 & 94.03 \\
\hline $\mathrm{C}_{2,6}^{\prime}$ in tricin $\left(\mathrm{T}_{2}^{\prime}, 6\right)$ & 106.12 & 106.02 & 105.24 \\
\hline $\mathrm{C}_{3,5}$ in $(H)$ & 116.02 & 115.53 & 115.67 \\
\hline $\mathrm{C}_{2,6}$ in $(H)$ & 129.86 & 128.30 & 129.01 \\
\hline $\mathrm{C}_{3}$ and $\mathrm{C}_{4}$ in etherified guaiacyl $(G)$ & 147.74 & 147.52 & 147.74 \\
\hline $\mathrm{C}_{\alpha}$ in $\beta$-O-4' substructure $\left(\mathrm{A}_{\gamma}\right)$ linked units with $\alpha \mathrm{C}=\mathrm{O}$ & 153.48 & 153.41 & 152.99 \\
\hline $\mathrm{C}_{4}$ in $(H)$ & - & 159.72 & 162.21 \\
\hline $\mathrm{C}=\mathrm{O}$ in spirodienone units & - & - & 182.78 \\
\hline $\mathrm{C}=\mathrm{O}$ in aromatic aldehyde & 189.80 & - & - \\
\hline$\alpha \mathrm{C}=\mathrm{O}$ in $\beta$-O-4' substructures $\left(\mathrm{A}_{\gamma}\right)$ linked units with & 196.76 & 195.05 & 193.64 \\
\hline
\end{tabular}

\section{Lignin depolymerization}

Several methods at lab and pilot scales have been investigated to valorise the polysaccharides into various chemicals through a biorefinery process (Wettstein et al., 2012; Diwan et al., 2020). Lignin was generated as a byproduct through a biorefinery process and is generally burned to generate both heat and used chemicals. Lignin valorisation is a substantial biorefinery pathway to reach the goal of maximum amounts of carbon efficacy.

We have investigated several methods including solid acids (Deepa and Dhepe, 2015), solid bases, (Chaudhary and Dhepe, 2017), homogenous ionic liquids (ILs) (Sandip K. Singh and Dhepe, 2016a; 2019) and heterogeneous ionic liquid (Sandip K. Singh and Dhepe, 2018c), to 
convert the various types of lignin to a large fraction of aromatic monomers. These catalysts have been screened and correlated with lignin conversion using a wide range of reaction conditions, including temperature, time, solvent, and pressure. We have screened a set of different ILs as a catalyst, and $\left[\mathrm{C}_{3} \mathrm{SO}_{3} \mathrm{HMIM}_{3}\left[\mathrm{HSO}_{4}\right]\right.$ IL investigated as an effective catalyst to depolymerize lignin to maximum amounts (78\%) of low molar mass aromatic fractions at $120{ }^{\circ} \mathrm{C}$ in $1 \mathrm{~h}$. Additionally, to enhance the catalyst activity and recyclability, we synthesized and investigated the I-BAIL as a heterogeneous catalyst to convert lignin to maximum amounts $(90 \%)$ of low molar mass aromatic fractions at $200{ }^{\circ} \mathrm{C}, 1 \mathrm{~h}$. Both homogeneous and heterogeneous catalysts were highly efficient to convert lignin to high yields of low molar mass aromatic fractions. Therefore, in this work, we investigated these two catalysts to convert lignin to aromatic fractions.

Catalytic reaction was performed in a batch mode using a Parr autoclave $(100 \mathrm{~mL}$, Parr autoclave, USA). Reaction conditions, lignin ( $2 w t . \%$ solution of $\mathrm{H}_{2} \mathrm{O}: \mathrm{CH}_{3} \mathrm{OH}, 1: 5 v / v=30$ $\mathrm{mL}), 120{ }^{\circ} \mathrm{C}$ for $\left[\mathrm{C}_{3} \mathrm{SO}_{3} \mathrm{HMIM}_{[}\left[\mathrm{HSO}_{4}\right](0.5 \mathrm{~g}), 1 \mathrm{~h}, 1000 \mathrm{rpm}\right.$, were applied (For details on reaction and work-up procedure, see Section S3, ESM). Organic solvents were used, including tetrahydrofuran (THF), ethyl acetate (EtOAc) and diethyl ether (DEE), to recover organic soluble low molar mass fractions of aromatic compounds. The polarity index for DEE, EtOAc, and THF are 2.8, 4.4, and 4.0, respectively. Fig. 6 shows the maximum amounts of organic solvent-soluble product yield obtained with WS-derived lignin. Un-structural morphologies (SEM images, Fig. S1, ESM), and the appearance of a high intense peak $\sim 1100 \mathrm{~cm}^{-1}$ for alkyl aryl ethers (C-O-C) (Rashid et al., 2016; Larkin, 2011) (Fig. 4), could be a plausible explanation for maximum yields from WS derived lignin. In a mechanistic study, the rate of acid-catalysed cleavage of ether bonds particularly $\beta-\mathrm{O}-4$, occurred second order of magnitude faster for hydrolysis relative to carbon-carbon bonds (Sturgeon et al., 2014). Additionally, lignin-derived from BG (I and II) has shown almost similar organic solvents soluble product yields.

We have screened a series of reaction conditions to have maximum amounts of low molecular weight aromatic products using an I-BAIL catalyst. Under the optimized reaction conditions, the autogenerated pressure (32 bar) due to methanol and water $(5: 1 \mathrm{v} / \mathrm{v})$ reaction medium, was noted (Sandip K. Singh and Dhepe, 2018c). Lignin-derived from WS showed (Fig. 6) the maximum amounts of organic solvent soluble products yield. It could be plausible explained based on the morphologies and a high intense ATR band at $\sim 1100 \mathrm{~cm}^{-1}$ for alky aryl ether linkages (Fig. 4). That indicates higher the ether linkages in lignin structure yielded the 
maximum amounts of lignin depolymerization product (Sturgeon et al., 2014). Moreover, lignin recovered from BG (I and II) crop residues showed similar catalytic results of organic solvent soluble products.

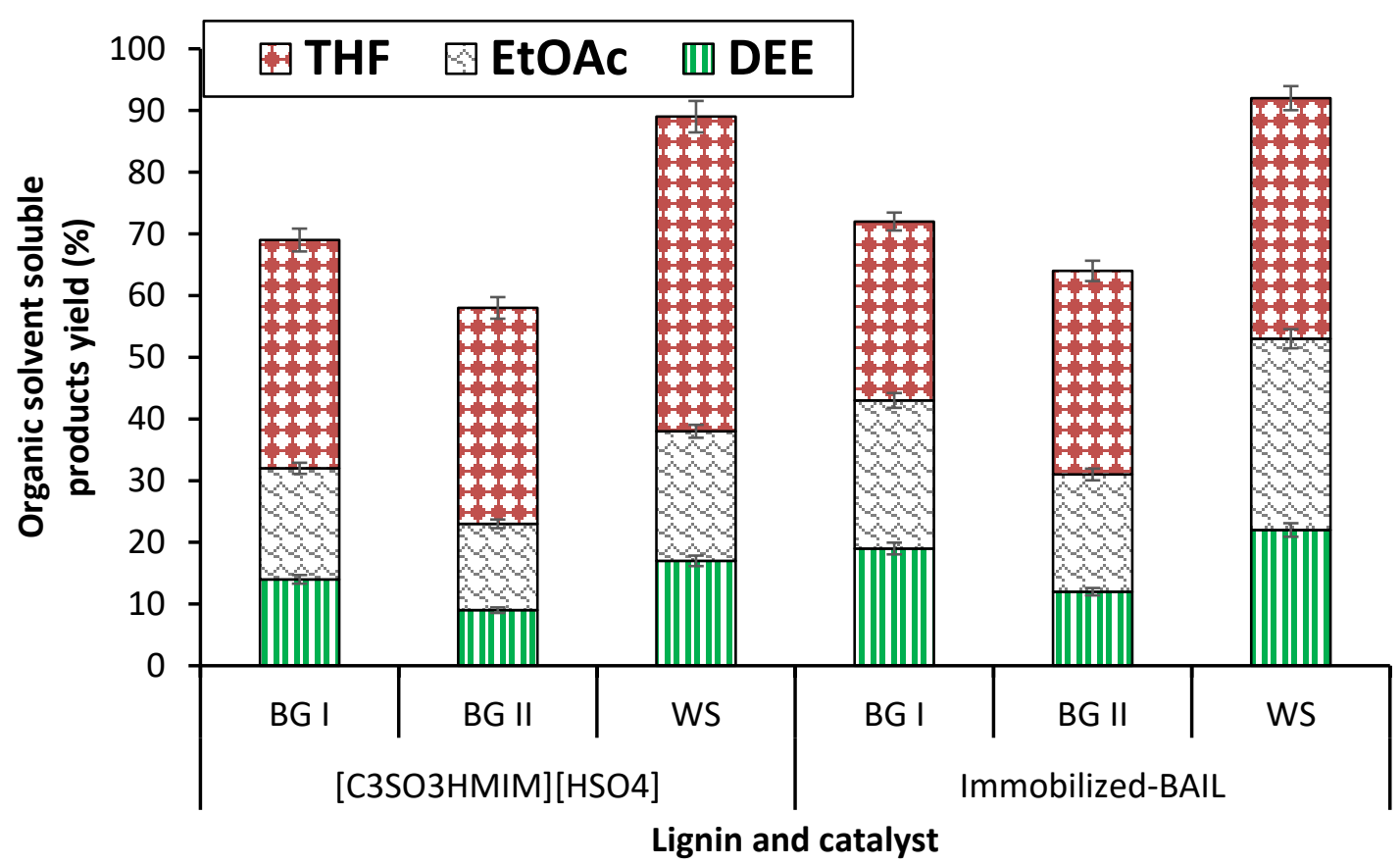

Fig. 6. Depolymerization of lignin using $\left[\mathrm{C}_{3} \mathrm{SO}_{3} \mathrm{HMIM}\right]\left[\mathrm{HSO}_{4}\right]$ BAIL and I-BAIL catalyst. Reaction condition: lignin ( 2 wt.\% solution $\mathrm{H}_{2} \mathrm{O}: \mathrm{CH}_{3} \mathrm{OH}, 1: 5 v / v=30 \mathrm{~mL}$ ), $120{ }^{\circ} \mathrm{C}$ for $\left[\mathrm{C}_{3} \mathrm{SO}_{3} \mathrm{HMIM}\right]\left[\mathrm{HSO}_{4}\right](0.5 \mathrm{~g})$, and $200{ }^{\circ} \mathrm{C}$ for I-BAIL $(0.5 \mathrm{~g}), 1 \mathrm{~h}, 1000 \mathrm{rpm}$.

\section{Conclusions}

In summary, quantification of alpha-, beta- and gamma- cellulose in crop residues, is a substantial way to balance the carbon efficacy during the production of biofuels or chemicals from polysaccharides. Two-stage concentrated, and dilute sulfuric acid hydrolysis lignin was recovered, characterized and correlated the impacts of their properties for depolymerization. These two studies in this work can add more economical values to the biorefinery process for biofuels or chemical production. Our experimental designs and significant findings in this work, are shown as below;

1. Three crop residues (two BG I and II and WS) were processed for determination of alpha-, beta- and gamma- cellulose, pentosan, nutrients, silica, and lignin.

2. BG crop residues yielded the maximum amounts of structural biopolymers, (i.e., holocellulose, pentosan and lignin) relative to WS. 
3. Recovered lignin samples were thoroughly characterized using bulk and molecular levels analytical techniques including elemental analysis, TGA, UV-Vis, SEM, XRD, ATR, ${ }^{13} \mathrm{C}$ CP-MAS NMR.

4. ATR spectrum of WS derived lignin showed a high intensity for carbon-oxygen-carbon bonds (i.e., $\mathrm{C}-\mathrm{O}-\mathrm{C}$ ).

5. ${ }^{13} \mathrm{C}$ CP-MAS NMR showed the appearance of tricin in all lignin samples while the dibenzodioxocin and spirodienone substructures are appeared in WS derived lignin.

6. Lignin recovered from WS showed the maximum amounts of depolymerized organic solvent soluble products yield by using both homogenous and heterogeneous catalysts.

7. The maximum amounts of organic soluble products yield correlated with the lignin morphologies (SEM) and the presence of ether and/or ester linkage in lignin (ATR).

\section{Acknowledgements}

SKS and BMM thank the Council of Scientific and Industrial Research (CSIR), New Delhi, India, for the Research Fellowship.

\section{Electronic Supplementary materials (ESM)}

Composition analysis, characterisation, depolymerization and work-up.

\section{References}

Alinejad, M., Henry, C., Nikafshar, S., Gondaliya, A., Bagheri, S., Chen, N., et al. (2019) Lignin-Based Polyurethanes: Opportunities for Bio-Based Foams, Elastomers, Coatings and Adhesives. Polymers 11:1202. https://www.mdpi.com/2073-4360/11/7/1202.

Almendros, G., Martinez, A. T., Gonzalez, A. E., Gonzalez-Vila, F. J., Fruend, R., \& Luedemann, H. D. (1992) CPMAS carbon-13 NMR study of lignin preparations from wheat straw transformed by five lignocellulose-degrading fungi. Journal of Agricultural and Food Chemistry 40:1297-1302. doi:10.1021/jf00019a043.

Alpha-, beta- and gamma-cellulose in pulp (T $203 \mathrm{~cm}-99,1999)$. Technical Association of the Pulp and Paper Industry (U.S.) 1-5.

Antosiewicz, J. M., \& Shugar, D. (2016) UV-Vis spectroscopy of tyrosine side-groups in studies of protein structure. Part 2: selected applications. Biophysical reviews 8:163-177. doi:10.1007/s12551-016-0197-7.

Bhalla, A., Cai, C. M., Xu, F., Singh, S. K., Bansal, N., Phongpreecha, T., et al. (2019) Performance of three delignifying pretreatments on hardwoods: hydrolysis yields, comprehensive mass balances, and lignin properties (journal article). Biotechnology for Biofuels 12:213. doi:10.1186/s13068-019-1546-0.

Binder, J. B., \& Raines, R. T. (2010) Fermentable sugars by chemical hydrolysis of biomass. Proc Natl Acad Sci USA 107:4516 - 4521.

Bray, M. W., \& Andrews, T. M. (1923) An Improved Method for the Determination of Alpha, Beta-, and Gamma-Cellulose. Industrial \& Engineering Chemistry 15:377-378. doi:10.1021/ie50160a024. 
Chaudhary, R., \& Dhepe, P. L. (2017) Solid base catalyzed depolymerization of lignin into low molecular weight products (10.1039/C6GC02701F). Green Chemistry 19:778-788. doi:10.1039/C6GC02701F.

Chaudhary, R., \& Dhepe, P. L. (2019) Depolymerization of Lignin Using a Solid Base Catalyst. Energy \& Fuels 33:4369-4377. doi:10.1021/acs.energyfuels.9b00621.

Constant, S., Wienk, H. L. J., Frissen, A. E., Peinder, P. d., Boelens, R., van Es, D. S., et al. (2016) New insights into the structure and composition of technical lignins: a comparative characterisation study (10.1039/C5GC03043A). Green Chemistry 18:2651-2665. doi:10.1039/C5GC03043A.

Corma, A., Iborra, S., \& Velty, A. (2007) Chemical Routes for the Transformation of Biomass into Chemicals. Chemical Reviews 107:2411-2502. doi:10.1021/cr050989d.

Deepa, A. K., \& Dhepe, P. L. (2015) Lignin Depolymerization into Aromatic Monomers over Solid Acid Catalysts. ACS Catalysis 5:365-379. doi:10.1021/cs501371q.

del Río, J. C., Lino, A. G., Colodette, J. L., Lima, C. F., Gutiérrez, A., Martínez, Á. T., et al. (2015) Differences in the chemical structure of the lignins from sugarcane bagasse and straw. Biomass and Bioenergy 81:322-338. doi:https://doi.org/10.1016/j.biombioe.2015.07.006.

Diwan, B., Mukhopadhyay, D., \& Gupta, P. (2020). Recent trends in biorefinery-based valorisation of lignocellulosic biomass. In N. Krishnaraj Rathinam, \& R. K. Sani (Eds.), Biovalorisation of Wastes to Renewable Chemicals and Biofuels (pp. 219-242). Elsevier. doi:https://doi.org/10.1016/B978-0-12-817951-2.00011-0.

Ghaffar, S. H., \& Fan, M. (2013) Structural analysis for lignin characteristics in biomass straw. Biomass and Bioenergy 57:264-279. doi:https://doi.org/10.1016/j.biombioe.2013.07.015.

Gomide, R. A. C., de Oliveira, A. C. S., Rodrigues, D. A. C., de Oliveira, C. R., de Assis, O. B. G., Dias, M. V., et al. (2020) Development and Characterization of Lignin Microparticles for Physical and Antioxidant Enhancement of Biodegradable Polymers. Journal of Polymers and the Environment 28:1326-1334. doi:10.1007/s10924-020-01685$\mathrm{Z}$.

H. M. Ng, Norshahirah M. Saidi, Fatin Saiha Omar, K. Ramesh, S. Ramesh, \& Bashir, S. (2018). Thermogravimetric Analysis of Polymers. Encyclopedia of Polymer Science and Technology (pp. 1-29). John Wiley \& Sons. doi:10.1002/0471440264.pst667.

Hatfield, G. R., Maciel, G. E., Erbatur, O., \& Erbatur, G. (1987) Qualitative and quantitative analysis of solid lignin samples by carbon-13 nuclear magnetic resonance spectrometry. Analytical Chemistry 59:172-179. doi:10.1021/ac00128a036.

Hergert, H. L. (1971). Infrares Spectra. In K. V. Sarkanen, \& C. H. Ludwig (Eds.), Lignins: occurrence, formation, structure and reactions (pp. 267-293). New York: WileyInterscience.

Holtman, K. M., Chang, H. m., Jameel, H., \& Kadla, J. F. (2006) Quantitative 13C NMR Characterization of Milled Wood Lignins Isolated by Different Milling Techniques. Journal of Wood Chemistry and Technology 26:21-34. doi:10.1080/02773810600582152.

Hussin, M. H., Rahim, A. A., Mohamad Ibrahim, M. N., \& Brosse, N. (2013) Physicochemical characterization of alkaline and ethanol organosolv lignins from oil palm (Elaeis guineensis) fronds as phenol substitutes for green material applications. Industrial Crops and Products 49:23-32. doi:http://dx.doi.org/10.1016/j.indcrop.2013.04.030.

Kozliak, E. I., Kubátová, A., Artemyeva, A. A., Nagel, E., Zhang, C., Rajappagowda, R. B., et al. (2016) Thermal Liquefaction of Lignin to Aromatics: Efficiency, Selectivity, and Product Analysis. ACS Sustainable Chemistry \& Engineering 4:5106-5122. doi:10.1021/acssuschemeng.6b01046.

Kumar, P. S., Ramakrishnan, K., Kirupha, S. D., \& Sivanesan, S. (2010) Thermodynamic and kinetic studies of cadmium adsorption from aqueous solution onto rice husk. Brazilian 
Journal of Chemical Engineering

27:347-355.

http://www.scielo.br/scielo.php?script=sci_arttext\&pid=S0104-

$66322010000200013 \&$ nrm=iso.

Larkin, P. (2011). Illustrated IR and Raman Spectra Demonstrating Important Functional Groups. Infrared and Raman Spectroscopy Principles and Spectral Interpretation (pp. 135176). Elsevier. doi:10.1016/B978-0-12-386984-5.10008-4.

Li, W., Sun, N., Stoner, B., Jiang, X., Lu, X., \& Rogers, R. D. (2011) Rapid dissolution of lignocellulosic biomass in ionic liquids using temperatures above the glass transition of lignin (10.1039/C1GC15522A). Green Chemistry 13:2038-2047. doi:10.1039/C1GC15522A.

Li, Y., Shuai, L., Kim, H., Motagamwala, A. H., Mobley, J. K., Yue, F., et al. (2018) An "ideal lignin" facilitates full biomass utilization. Science Advances 4:eaau2968. doi:10.1126/sciadv.aau2968.

Long, J., Li, X., Guo, B., Wang, F., Yu, Y., \& Wang, L. (2012) Simultaneous delignification and selective catalytic transformation of agricultural lignocellulose in cooperative ionic liquid pairs (10.1039/C2GC35105F). Green Chemistry 14:1935-1941. doi:10.1039/C2GC35105F.

Lynd, L. R., Cushman, J. H., Nichols, R. J., \& Wyman, C. E. (1991) Fuel Ethanol from Cellulosic Biomass. Science 251:1318-1323. doi:10.1126/science.251.4999.1318.

M. Shahbandeh (2020). Global sugar production by leading country 2018/2019, https://www.statista.com/statistics/495973/sugar-production-worldwide/.

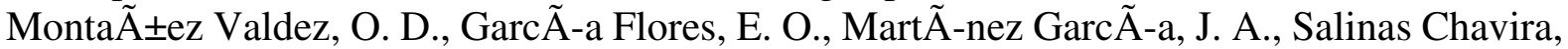
J., Rojo Rubio, R., \& Germ $\tilde{A}_{i n}$ Peralta Ortiz, J. J. s. (2008) Use of Pleurotus Pulmonarius to change the nutritional quality of wheat straw. I: Effect on chemical composition. Interciencia

$33: 435-438$.

http://www.scielo.org.ve/scielo.php?script=sci_arttext\&pid=S0378$18442008000600009 \&$ nrm $=$ iso.

Mosier, N., Wyman, C., Dale, B., Elander, R., Lee, Y. Y., Holtzapple, M., et al. (2005) Features of promising technologies for pretreatment of lignocellulosic biomass. Bioresource Technology 96:673-686. doi:https://doi.org/10.1016/j.biortech.2004.06.025.

Musha, Y., \& Goring, D. A. I. (1975) Distribution of syringyl and guaiacyl moieties in hardwoods as indicated by ultraviolet microscopy. Wood Science and Technology 9:4558. doi:10.1007/BF00351914.

Nimz, H. H., Robert, D., Faix, O., \& Nemr, M. (1981) Carbon-13 NMR Spectra of Lignins, 8. Structural Differences between Lignins of Hardwoods, Softwoods, Grasses and Compression Wood. Holzforschung 35:16. doi:https://doi.org/10.1515/hfsg.1981.35.1.16.

Oh, S. Y., Yoo, D. I., Shin, Y., Kim, H. C., Kim, H. Y., Chung, Y. S., et al. (2005) Crystalline structure analysis of cellulose treated with sodium hydroxide and carbon dioxide by means of X-ray diffraction and FTIR spectroscopy. Carbohydrate Research 340:2376-2391. doi:http://dx.doi.org/10.1016/j.carres.2005.08.007.

Pimentel, D., \& Burgess, M. (2014) Biofuel production using food. Environment, Development and Sustainability 16:1-3. doi:10.1007/s10668-013-9505-6.

Ragauskas, A. J., Williams, C. K., Davison, B. H., Britovsek, G., Cairney, J., Eckert, C. A., et al. (2006) The Path Forward for Biofuels and Biomaterials. Science 311:484-489. doi:10.1126/science.1114736.

Rashid, T., Kait, C. F., \& Murugesan, T. (2016) A "Fourier Transformed Infrared" Compound Study of Lignin Recovered from a Formic Acid Process. Procedia Engineering 148:13121319. doi:https://doi.org/10.1016/j.proeng.2016.06.547.

Rezende, C., de Lima, M., Maziero, P., deAzevedo, E., Garcia, W., \& Polikarpov, I. (2011) Chemical and morphological characterization of sugarcane bagasse submitted to a 
delignification process for enhanced enzymatic digestibility. Biotechnology for Biofuels C7 - 54 4:1-19. doi:10.1186/1754-6834-4-54.

Riaz, A., Kim, C. S., Kim, Y., \& Kim, J. (2016) High-yield and high-calorific bio-oil production from concentrated sulfuric acid hydrolysis lignin in supercritical ethanol. Fuel 172:238-247. doi:https://doi.org/10.1016/j.fuel.2015.12.051.

Rinaldi, R., Jastrzebski, R., Clough, M. T., Ralph, J., Kennema, M., Bruijnincx, P. C. A., et al. (2016) Paving the Way for Lignin Valorisation: Recent Advances in Bioengineering, Biorefining and Catalysis. Angewandte Chemie International Edition 55:8164-8215. doi:https://doi.org/10.1002/anie.201510351.

Samuel, R., Pu, Y., Raman, B., \& Ragauskas, A. J. (2010) Structural characterization and comparison of switchgrass ball-milled lignin before and after dilute acid pretreatment. Appl Biochem Biotechnol 162:62-74. doi:10.1007/s12010-009-8749-y.

Sandford, P. A., \& Baird, J. (1983). 7 - Industrial Utilization of Polysaccharides. In G. O. Aspinall (Ed.), The Polysaccharides (pp. 411-490). Academic Press. doi:https://doi.org/10.1016/B978-0-12-065602-8.50012-1.

Sannigrahi, P., Ragauskas, A. J., \& Miller, S. J. (2008) Effects of Two-Stage Dilute Acid Pretreatment on the Structure and Composition of Lignin and Cellulose in Loblolly Pine (journal article). BioEnergy Research 1:205-214. doi:10.1007/s12155-008-9021-y.

Sannigrahi, P., Ragauskas, A. J., \& Miller, S. J. (2010) Lignin Structural Modifications Resulting from Ethanol Organosolv Treatment of Loblolly Pine. Energy \& Fuels 24:683689. doi:10.1021/ef900845t.

Sarkanen, K. V. (1963). In The Chemistry of Wood. New York: Browning, B. L., Ed.; Interscience.

Schutyser, W., Renders, T., Van den Bosch, S., Koelewijn, S. F., Beckham, G. T., \& Sels, B. F. (2018) Chemicals from lignin: an interplay of lignocellulose fractionation, depolymerisation, and upgrading (10.1039/C7CS00566K). Chemical Society Reviews 47:852-908. doi:10.1039/C7CS00566K.

Shahbandeh, M. (2020) Global leading wheat producers 2019/2020. Global leading wheat producers 2019/2020; https://www.statista.com/statistics/237912/global-top-wheatproducing-countries/.

Shulga, G., VitoljFa, S., Shakels, V., Belkova, L., Cazacu, G., Vasile, C., et al. (2012) Lignin Separated from the Hydrolyzate of the Hydrothermal Treatment of Birch Wood and Its Surface Properties. Cellulose Chemistry and Technology 46:307-318.

Singh, S. K. (2019) Solubility of lignin and chitin in ionic liquids and their biomedical applications. International Journal of Biological Macromolecules 132:265-277. doi:https://doi.org/10.1016/j.ijbiomac.2019.03.182.

Singh, S. K. (2020) Biological treatment of plant biomass and factors affecting bioactivity. Journal of Cleaner Production 123546. doi:https://doi.org/10.1016/j.jclepro.2020.123546.

Singh, S. K., Banerjee, S., Vanka, K., \& Dhepe, P. L. (2018) Understanding interactions between lignin and ionic liquids with experimental and theoretical studies during catalytic depolymerisation. Catalysis Today 309:98-108. doi:https://doi.org/10.1016/j.cattod.2017.09.050.

Singh, S. K., \& Dhepe, P. L. (2016a) Ionic liquids catalyzed lignin liquefaction: mechanistic studies using TPO-MS, FT-IR, RAMAN and 1D, 2D-HSQC/NOESY NMR (10.1039/C6GC00771F). Green Chemistry 18:4098-4108. doi:10.1039/C6GC00771F.

Singh, S. K., \& Dhepe, P. L. (2016b) Isolation of lignin by organosolv process from different varieties of rice husk: Understanding their physical and chemical properties. Bioresource Technology 221:310-317. doi:https://doi.org/10.1016/j.biortech.2016.09.042. 
Singh, S. K., \& Dhepe, P. L. (2018a) Effect of structural properties of organosolv lignins isolated from different rice husks on their liquefaction using acidic ionic liquids (journal article). Clean Technol. Environ. Policy 20:739-750. doi:10.1007/s10098-017-1435-9.

Singh, S. K., \& Dhepe, P. L. (2018b) Experimental evidences for existence of varying moieties and functional groups in assorted crop waste derived organosolv lignins. Industrial Crops and Products 119:144-151. doi:https://doi.org/10.1016/j.indcrop.2018.04.002.

Singh, S. K., \& Dhepe, P. L. (2018c) Novel Synthesis of Immobilized Brønsted- Acidic Ionic Liquid: Application in Lignin Depolymerization. ChemistrySelect 3:5461-5470. doi:10.1002/slct.201703050.

Singh, S. K., \& Dhepe, P. L. (2019) Lignin Conversion Using Catalytic Ionic Liquids: Understanding the Role of Cations, Anions, and Hammett Acidity Functions. Industrial \& Engineering Chemistry Research 58:21273-21284. doi:10.1021/acs.iecr.9b03375.

Singh, S. K., \& Savoy, A. W. (2020) Ionic liquids synthesis and applications: An overview. Journal of Molecular Liquids doi:https://doi.org/10.1016/j.molliq.2019.112038.

Singh, S. K., Savoy, A. W., Yuan, Z., Luo, H., Stahl, S. S., Hegg, E. L., et al. (2019) Integrated Two-Stage Alkaline-Oxidative Pretreatment of Hybrid Poplar. Part 1: Impact of Alkaline Pre-Extraction Conditions on Process Performance and Lignin Properties. Industrial \& Engineering Chemistry Research 58:15989-15999. doi:10.1021/acs.iecr.9b01124.

Somerville, C. (2006) The Billion-Ton Biofuels Vision. Science 312:1277-1277. doi:10.1126/science.1130034.

Strassberger, Z., Prinsen, P., Klis, F. v. d., Es, D. S. v., Tanase, S., \& Rothenberg, G. (2015) Lignin solubilisation and gentle fractionation in liquid ammonia (10.1039/C4GC01143K). Green Chemistry 17:325-334. doi:10.1039/C4GC01143K.

Sturgeon, M. R., Kim, S., Lawrence, K., Paton, R. S., Chmely, S. C., Nimlos, M., et al. (2014) A Mechanistic Investigation of Acid-Catalyzed Cleavage of Aryl-Ether Linkages: Implications for Lignin Depolymerization in Acidic Environments. ACS Sustainable Chemistry \& Engineering 2:472-485. doi:10.1021/sc400384w.

Tang, S., Baker, G. A., Ravula, S., Jones, J. E., \& Zhao, H. (2012) PEG-functionalized ionic liquids for cellulose dissolution and saccharification (10.1039/C2GC35631G). Green Chemistry 14:2922-2932. doi:10.1039/C2GC35631G.

Templeton, D. W., Scarlata, C. J., Sluiter, J. B., \& Wolfrum, E. J. (2010) Compositional Analysis of Lignocellulosic Feedstocks. 2. Method Uncertainties. Journal of Agricultural and Food Chemistry 58:9054-9062. doi:10.1021/jf100807b.

Tenenbaum, D. J. (2008) Food vs. Fuel: Diversion of Crops Could Cause More Hunger. Environmental Health Perspectives 116:A254-A257. doi:doi:10.1289/ehp.116-a254.

Vanholme, R., De Meester, B., Ralph, J., \& Boerjan, W. (2019) Lignin biosynthesis and its integration into metabolism. Current Opinion in Biotechnology 56:230-239. doi:https://doi.org/10.1016/j.copbio.2019.02.018.

Wells, S. D. (1921) The Chemical Constitution of Soda and Sulfate Pulps from Coniferous Woods and Their Bleaching Qualities. Journal of Industrial \& Engineering Chemistry 13:936-939. doi:10.1021/ie50142a027.

Wettstein, S. G., Alonso, D. M., Gürbüz, E. I., \& Dumesic, J. A. (2012) A roadmap for conversion of lignocellulosic biomass to chemicals and fuels. Current Opinion in Chemical Engineering 1:218-224. doi:https://doi.org/10.1016/j.coche.2012.04.002.

Wu, Y., Fu, Z., Yin, D., Xu, Q., Liu, F., Lu, C., et al. (2010) Microwave-assisted hydrolysis of crystalline cellulose catalyzed by biomass char sulfonic acids (10.1039/B917807D). Green Chemistry 12:696-700. doi:10.1039/B917807D. 
Figures

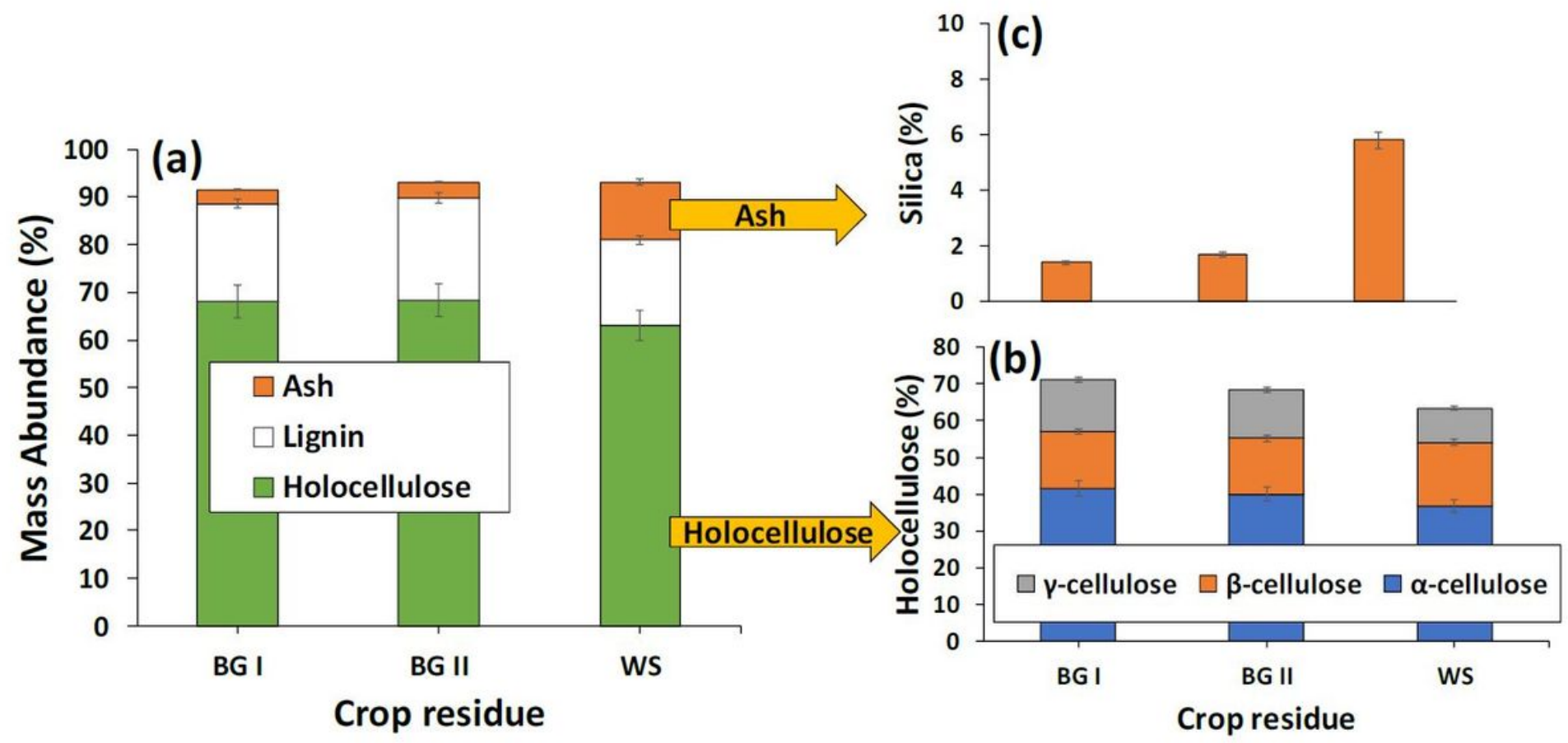

Figure 1

Composition analysis of BG I and II and WS. (a) mass abundance (b) holocellulose (i.e., alpha-, beta- and gamma-cellulose) fraction, and (c) silica content in ash fraction. 


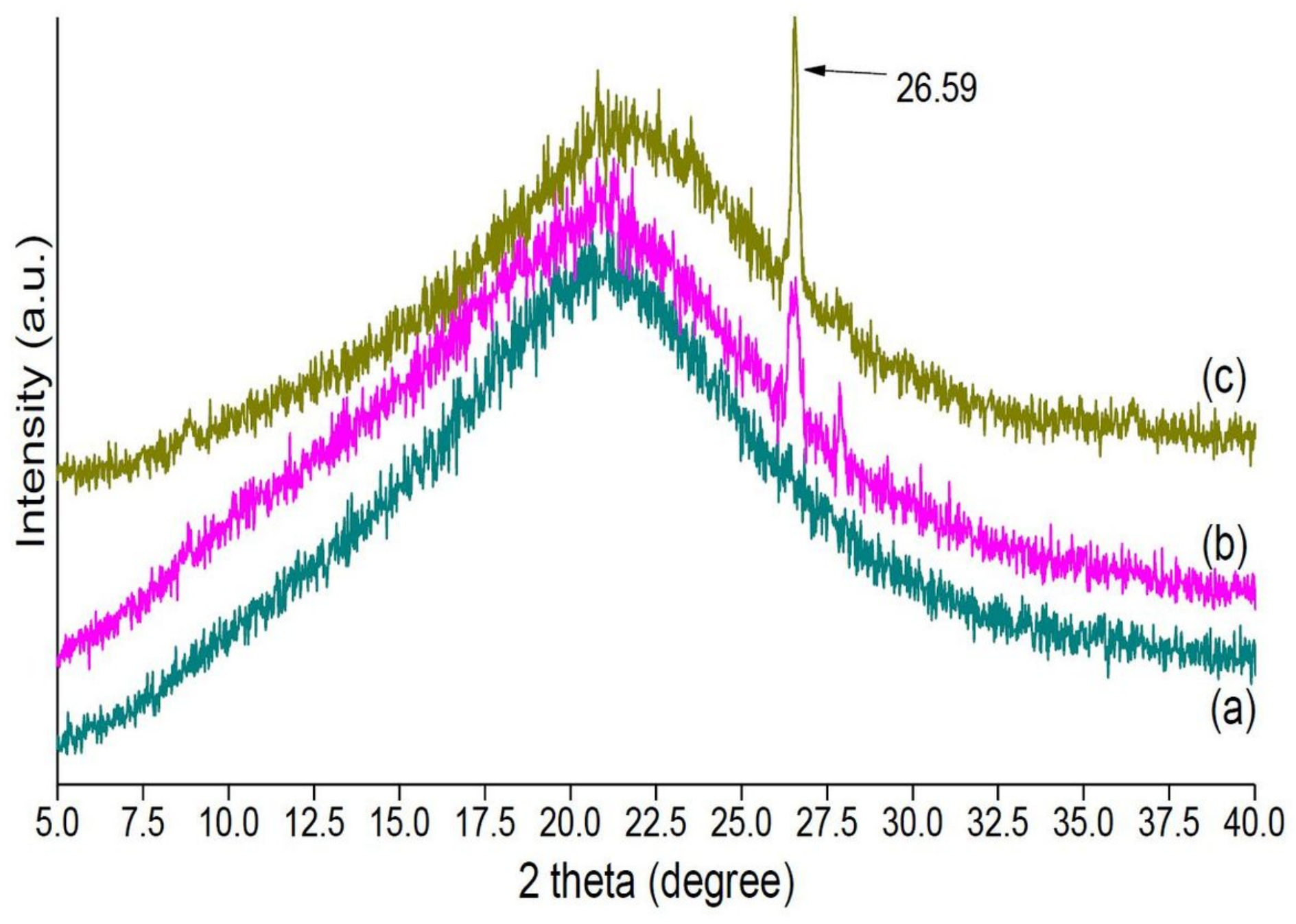

Figure 2

XRD spectra of (a) BG I, (b) BG II, (c) WS, recovered lignin. 


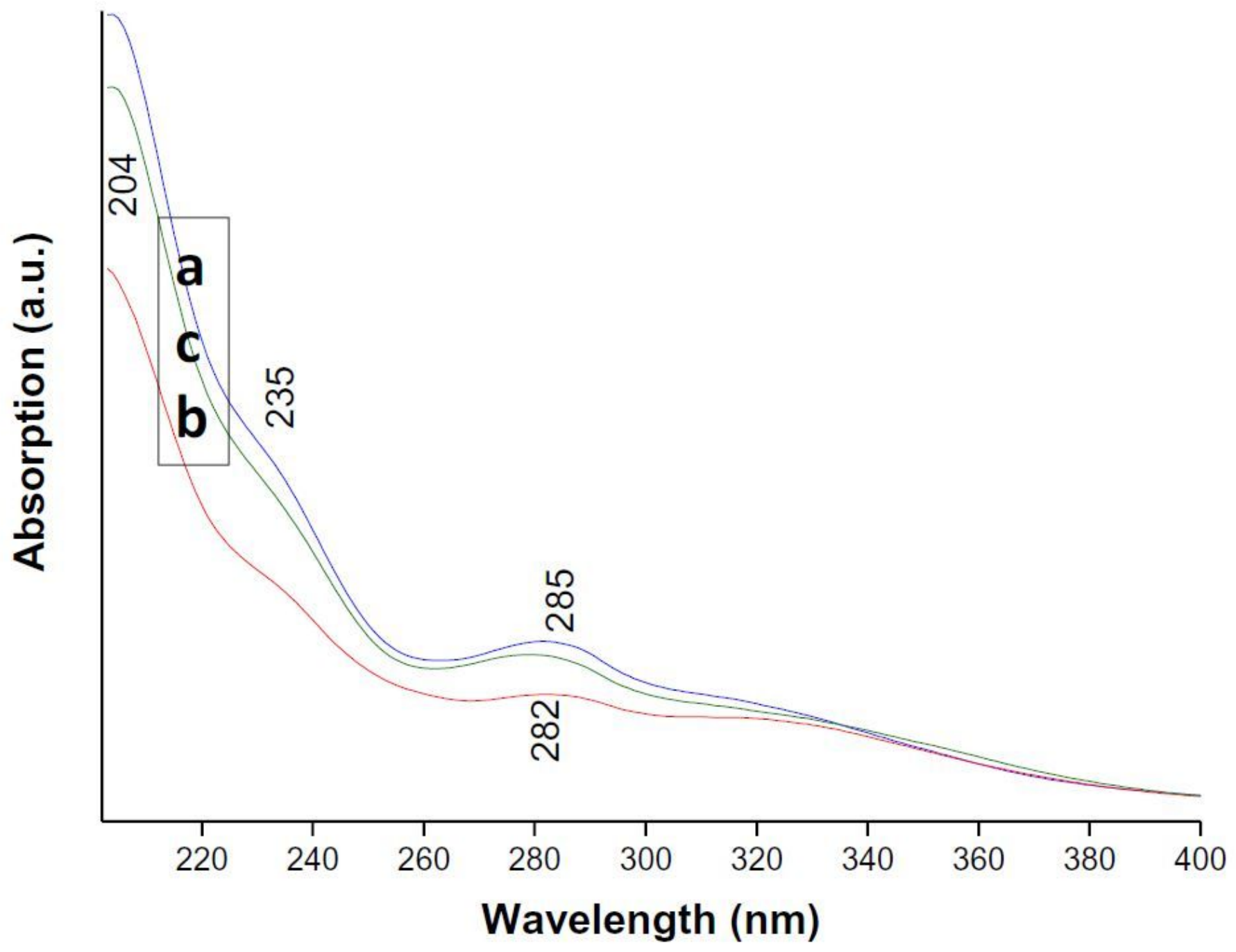

Figure 3

UV-Visible spectra of a- BG I, b- BG II and c- WS, recovered lignin. Note: $\sim 0.01 \% \mathrm{wt} / \mathrm{v}$ lignin solution prepared in methanol. 


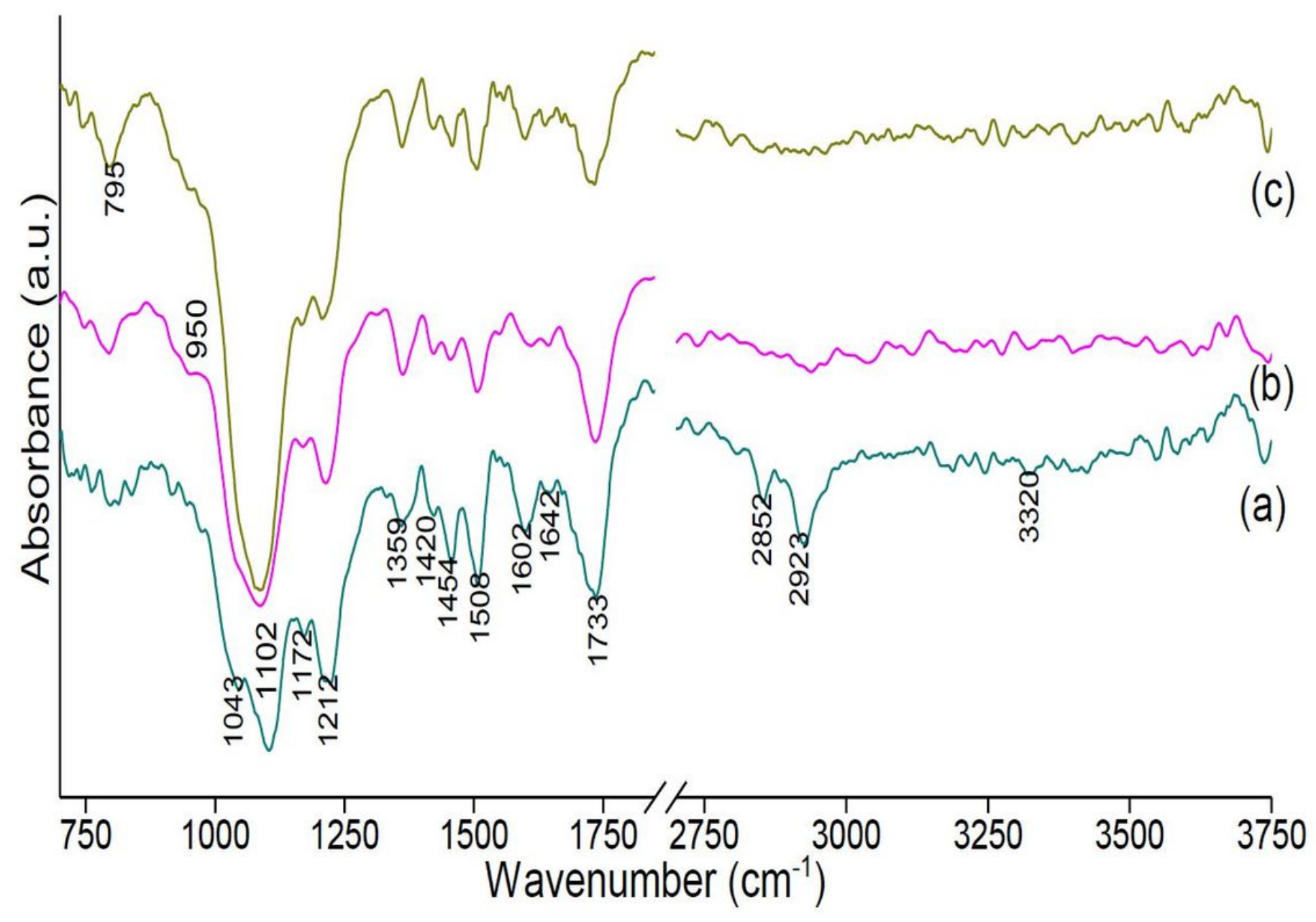

Figure 4

ATR spectra of recovered lignin from (a) BG I, (b) BG II, and (c) WS. 
(c)

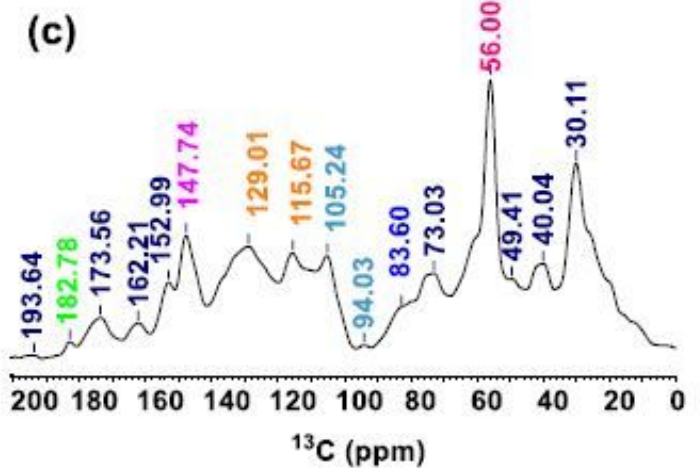

(b)
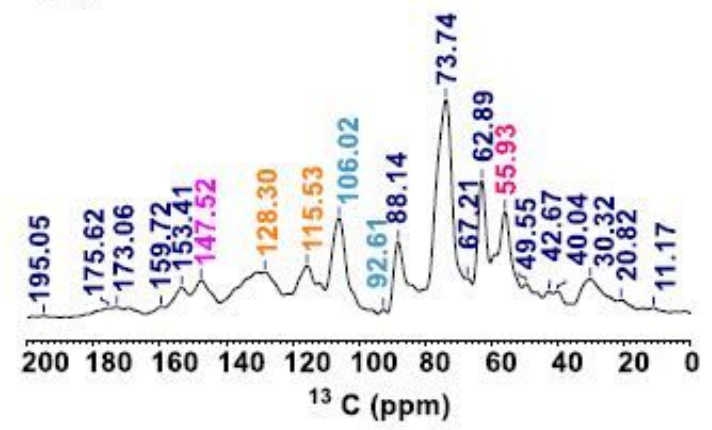

(a)

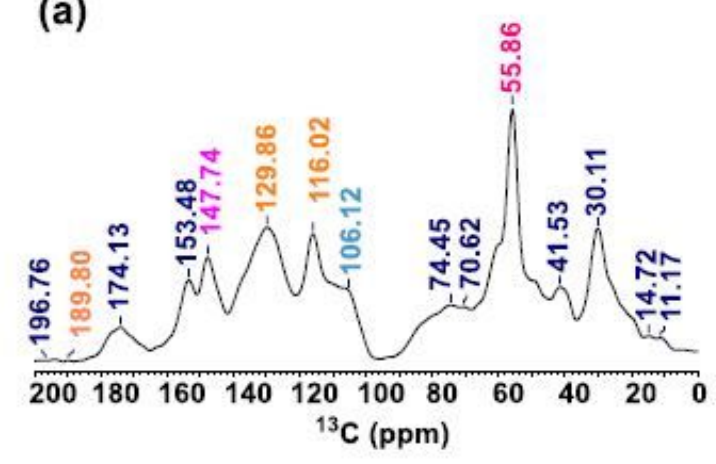

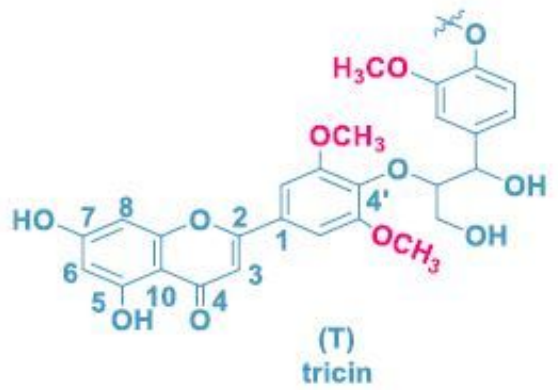

tricin

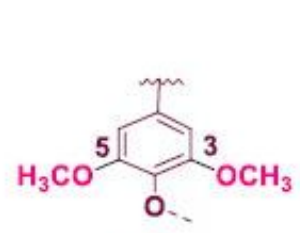

(S)

syringyl

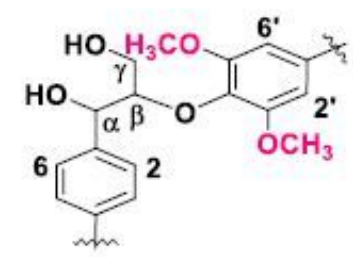

(A)

$\beta-0-4^{\prime}$ linkages

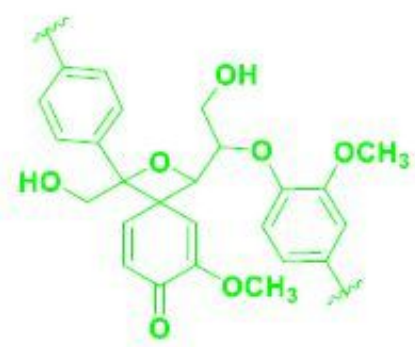

(B)

spirodienone

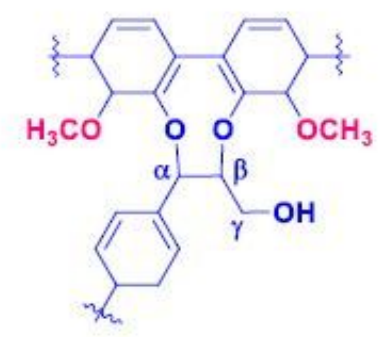

(C) dibenzodioxocin, $\left(5^{\prime}-5^{\prime \prime}, \alpha-0-4 / \beta-0-4 / \alpha-\beta\right)$

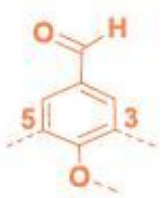

benzaldehyde

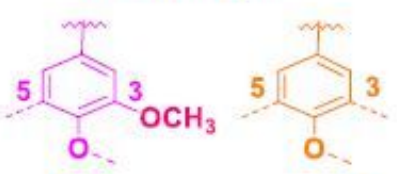

(G) guaiacyl p-hydroxyphenyl

\section{Figure 5}

Solid state 13C CP-MAS NMR spectra of lignin derived from (a) BG I, (b) BG II and (c) WS. 


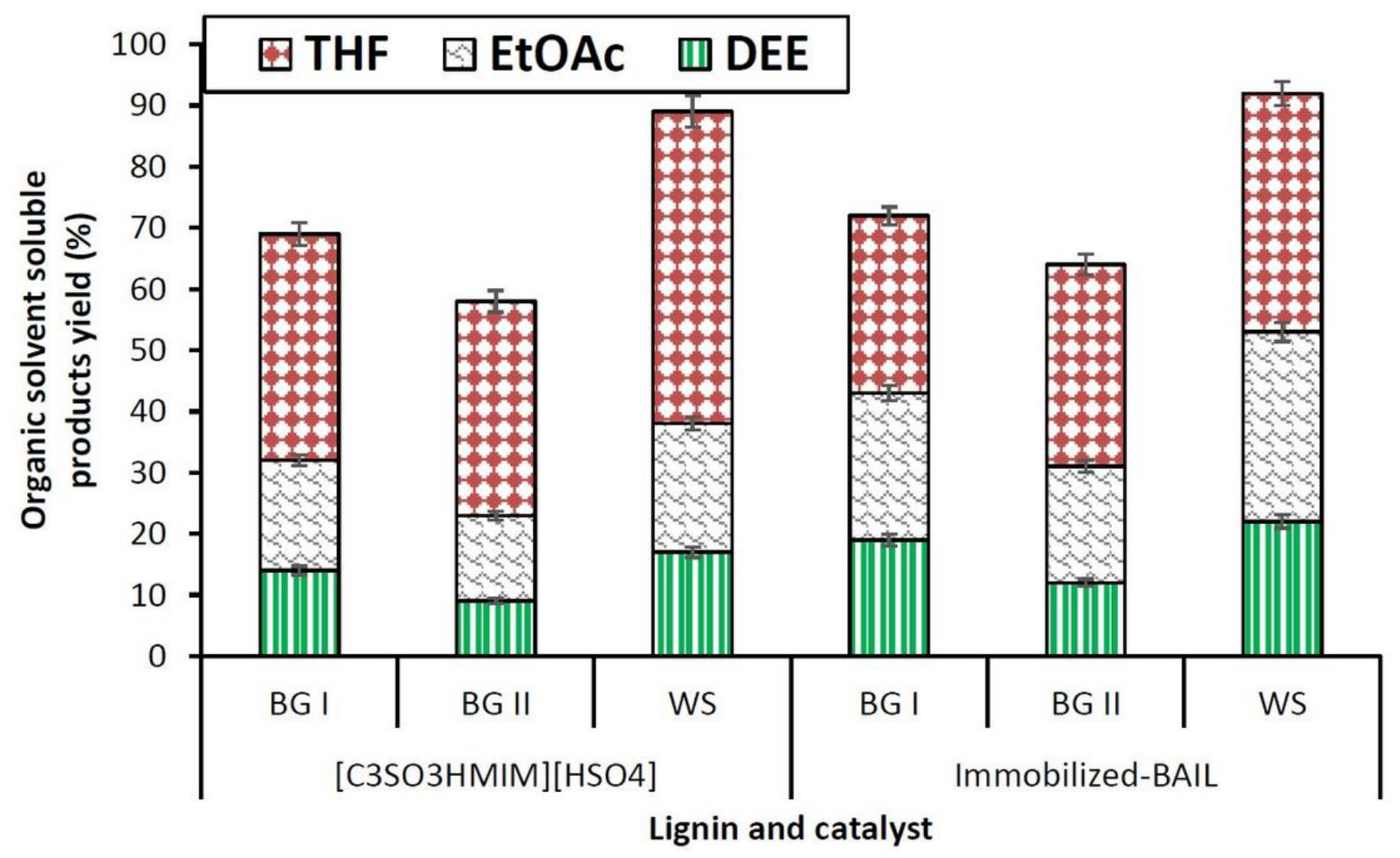

Figure 6

Depolymerization of lignin using [C3SO3HMIM][HSO4] BAIL and I-BAIL catalyst. Reaction condition: lignin (2 wt.\% solution $\mathrm{H} 2 \mathrm{O}: \mathrm{CH} 3 \mathrm{OH}, 1: 5 \mathrm{v} / \mathrm{v}=30 \mathrm{~mL}$ ), $120 \otimes$ for [C3SO3HMIM][HSO4] (0.5 g), and $200 \mathrm{oC}$ for IBAIL $(0.5 \mathrm{~g}), 1 \mathrm{~h}, 1000 \mathrm{rpm}$.

\section{Supplementary Files}

This is a list of supplementary files associated with this preprint. Click to download.

- SD.pdf 